\title{
The Effect of Fox News on Health Behavior During COVID-19^
}

\author{
Elliott Ash $^{1}$, Sergio Galletta ${ }^{2,1}$, Dominik Hangartner ${ }^{1,4}$, Yotam Margalit ${ }^{3}$, Matteo \\ Pinna ${ }^{1}$ \\ ${ }^{1}$ ETH Zurich \\ ${ }^{2}$ University of Bergamo \\ ${ }^{3}$ Tel Aviv University \\ ${ }^{4}$ London School of Economics and Political Science
}

\begin{abstract}
In the early weeks of the 2020 coronavirus (COVID-19) pandemic, Fox News Channel advanced a skeptical narrative that downplayed the risks posed by the virus. We find that this narrative had significant consequences: in localities with higher Fox News viewership - exogenous due to random variation in channel positioning-people were less likely to adopt behaviors geared toward social distancing (e.g., staying at home) and consumed less goods in preparation (e.g., cleaning products, hand sanitizers, masks). Using original survey data, we find that the effect of Fox News came not merely from its long-standing distrustful stance toward science, but also due to program-specific content that minimized the COVID-19 threat.
\end{abstract}

This version: June 26, 2020 (First version: June 26, 2020)

${ }^{\star}$ We thank David Cai, Leo Picard, and Shir Raviv for outstanding research assistance. We thank Ewelina Laskowska for feedback on the manuscript.

Email addresses: ashe@ethz.ch (Elliott Ash), sergio.galletta@unibg.it (Sergio Galletta), dominik.hangartner@gess.ethz.ch (Dominik Hangartner), ymargalit@tau.ac.il (Yotam Margalit), matteo.pinna@gess.ethz.ch (Matteo Pinna) 


\section{Introduction}

An extensive empirical literature has examined the effects of media messaging on beliefs and behavior (for a recent review, see DellaVigna and La Ferrara (2015)). While these studies have documented many examples of media effects, they typically do so in contexts where the stakes are low, i.e., where accepting and following the information promulgated by the media has little impact on consumers' well-being. Yet, during the COVID-19 pandemic, the stakes could hardly have been higher: Citizens exposed to media coverage of the virus have had a strong incentive to obtain accurate information to inform their actions and to help protect themselves and their families.

Nonetheless, in the two months before COVID-19 reached the United States, the hosts of leading shows on Fox News Channel (FNC) expressed openly skeptical views of COVID-19 (Abutaleb et al., 2020; Badger and Quealy, 2020; Peters and Grynbaum, 2020). Were the beliefs and behavior of FNC viewers influenced by the skeptical coverage? Or rather, when push came to shove, did people rely on other sources of information and take the precautionary steps recommended by most scientists and health experts? Given the importance of behavioral responses such as self-isolation in reducing COVID19 growth rates, estimating the effect of media coverage on the public's behavior is of obvious import.

Yet estimating the impact of media coverage on viewers' responses to COVID-19 poses a formidable empirical challenge. The audiences of different news outlets vary across a range of characteristics such as ideology, education, and socio-economic status. Such non-random selection implies that typical observational studies cannot isolate the effect of watching one news channel over another on the beliefs and behaviors of their viewers. To get around this problem, we leverage the quasi-random assignment of channel positions in cable services across U.S. localities as an instrument to overcome the causal identification issue (Martin and Yurukoglu, 2017).

Our analysis provides causal evidence of the effect of exposure to Fox News on viewers' adherence to social distancing measures and preparedness for the pandemic. We use detailed information on COVID-19-related behavior, including cell-phone based tracking of time spent away from home and distance of travel. Using recent data on county-level cable news viewership and exploiting the channel positions as the instrument for Fox News exposure, we show that the skeptical messaging expressed in leading Fox News programs had a substantial impact. Our two-stage-least-squares estimates suggest that 
one standard deviation (SD) increase in Fox News viewership decreased the time spent at home by around 1.5 SD's and the dollars spent on purchasing protective goods such as masks by 0.1 SD's. These instrumental variable results are robust to a range of specification choices and placebo tests. In particular, we find no corresponding effects for viewership of the other two main cable news networks CNN and MSNBC.

Did these behavioral responses have a public-health impact in terms of illness? We produce analogous estimates using infections and deaths from COVID-19 as outcomes, and do not see a clear effect. While we estimate positive coefficients, they are noisy and not close to standard thresholds for statistical significance.

Finally, we investigate the mechanisms underlying the effect of Fox News on COVID19-related behavior with data from an original survey of the U.S population. Although Fox News has long promoted views generally distrustful of both science and scientific expertise (Feldman et al., 2012; Huertas and Kriegsman, 2014; Hmielowski et al., 2014), we show that the influence of the channel was not limited to the cumulative effect of this longstanding editorial stance. Rather, we find that viewers' behavior closely mirrored the specific content they saw on certain shows on the channel. Moreover, our results indicate that this correspondence between viewership and behavior was strong even within subsets of Republican and conservative viewers.

This research contributes to the small but rapidly growing literature on the social and political aspects of the COVID-19 pandemic. Allcott et al. (2020) document that conditional on other observables, Republicans engaged in fewer self-isolation actions in response to COVID-19. Egorov et al. (2020) find stronger social distancing in Russian cities with higher ethnic fractionalization and xenophobia. On media influence, Bursztyn et al. (2020) use time zone variation to show that viewership for particular Fox News shows has been associated with different corona health outcomes. Most relatedly, Simonov et al. (2020) use 2015 viewership data to show a relationship between Fox News viewership on mobility outcomes.

\section{Background: Cable News and COVID-19 Coverage}

The U.S. cable news market is dominated by three channels: CNN, Fox News Channel (FNC), and MSNBC. While the content shown by each network is the same nationwide, the channel positions in the lineup vary significantly across localities. As first documented by Martin and Yurukoglu (2017), channel positioning affects viewership (a lower number translates to more viewers), and the arbitrariness in position assignment induces 
exogenous variation in viewership. See Appendix Section A1 for more details on the cable networks and channel positions.

The main cable news channels differ in their ideological leanings and editorial stance. In particular, FNC has widely been regarded as representing a strong conservativeRepublican stance, often embracing (or feeding) the party's opposition to "big government" and skepticism of the science underlying concerns about climate change (Huertas et al.). In the case of the COVID-19 outbreak, Fox News initially took a very different tone from other mainstream media outlets in its coverage of the virus' threat. Indeed, Figure 1 presents the prevalence across channels of various phrases that were used in the public discussion to communicate skepticism of the threat posed by the virus. Clearly, phrases such as "normal flu", or "political weapon" (a phrase used by President Trump in reference to COVID-19) were far more prevalent in FNC coverage compared to that of CNN and MSNBC.

\section{Data}

Channel positions. Local channel lineups for FNC, MSNBC, and CNN come from Nielsen, with information about the area served by each cable system at the zip-code level. We use channel positions from 2016, and similar to Galletta and Ash (2019), we aggregate the data at the county level, by averaging zip-code-level channel positions with weighting by population size. To address the presence of outlier channels, we winsorize the variables at the top and bottom deciles. Finally, we standardize by dividing by the standard deviation.

Nielsen 2020 ratings. Television viewership by county of FNC, MSNBC and CNN is also provided by Nielsen. The measure is "ratings," which is proportional to the number of minutes that each household tuned in to each specific channel during the months of January and February 2020. We standardize ratings by the standard deviation.

Coronavirus cases and deaths. The confirmed COVID-19-related number of cases and number of deaths are based on the COVID-19 dashboard published by the Center for Systems Science and Engineering (CSSE) at Johns Hopkins University (Dong et al., 2020). CSSE aggregates information from the World Health Organization, the Center for Disease Control, state health departments, and other agencies. Information is reported daily at the county level. 
Mobility. SafeGraph provides information about individuals' mobility based on mobile phone device locations. The data is reported at the Census Block Group level (CBG), a small area with between 600 and 1300 people. For each device, the "home" is determined by the modal nighttime location for the device over the reporting period. We observe three mobility outcomes at the daily level. First, distance from home is the median distance traveled from home that day for households in that CBG. Second, Time outside home is the median time (in minutes) that an individual is outside the home during a particular day. Third, Full-time work is defined as the number of devices that spent six hours outside of the home during daylight work hours.

Shopping. Decadata provides transaction-level data on COVID-19-related products. These products are those deemed necessary in preparation of the COVID-19 threat and the possibility of a long stay at home. They include cleaning products, face masks, hand sanitizer, toilet paper, and face tissues. Transactions come from a set of around 1200 stores for 581 zipcodes in 10 states. The data include net and gross price and quantity sold for each product class, see SI for further details.

Demographics and Politics. The data on local demographics come from the 2010 U.S. Census. The benchmark regression specification includes the following set of controls, corresponding to the county or zipcode level depending on the outcome: population density, land area, working-age share of population aged 20-69 over other ages, proportion eligible for food stamps, proportion with no high school attended, proportion who attended college, a binary indicator for above-median black population share, a binary indicator for above-median white population share, and proportion male gender. Data on political attitudes includes binary indicators for above-median Republican vote share from the 2012 and 2016 presidential elections.

Survey Data. To tease out different mechanisms of media influence, we fielded an original survey of 1480 U.S. respondents. The national survey was implemented by the survey company Lucid between April 9-14th, 2020. The survey focuses on three dimensions of COVID-19 threat: behavior, beliefs, and policy preferences. First, we asked respondents about the time they last carried out activities and behaviors not complying with social distancing. Second, we measure beliefs related to COVID-19. We ask whether respondents believe that a drug such as Hydroxychloroquine is an effective treatment. This was a (mistaken) claim repeatedly promoted by President Trump, as well as Fox 
News shows, in the early weeks of the pandemic. Third, we ask respondents about their preferred policy response to COVID-19 concerning the trade-off between economic harms and health harms. Respondents place themselves on a 10-point scale about whether the government should focus on the economy or on public health. Beyond these outcome measures, we also asked respondents about which cable news channel and particular shows they watch. In addition, the survey provides a range of sociodemographic variables such as gender, age, education, race, location, as well as political ideology and party identity.

\section{Empirical Approach}

\subsection{Instrumental Variable Analysis}

We are interested in the relationship between FNC viewership and individuals' behavioral response to the spread of COVID-19 in U.S. localities. Since viewers select into watching channels and programs that fit their political preferences, a simple correlation of FNC viewership and health behavior will likely produce biased estimates of the effect of FNC programming. To overcome this self-selection, we apply the instrumental variables approach first proposed by Martin and Yurukoglu (2017), exploiting arbitrary variation in channels' position in the system lineup to exogenously shift viewership.

We specify the first-stage equation as:

$$
V_{i s}=\alpha+\gamma_{s}+\gamma Z_{i s}+\beta X_{i s}+\eta_{i s}
$$

where $V_{i}$ is FNC average viewership (ratings) in January-February 2020 and $Z_{i s}$, the instrument, is the FNC channel position in the system lineup in locality $i$. $\mathbf{X}_{i s}$ includes covariates that account for pre-determined locality characteristics as well as CNN and MSNBC viewership. $\gamma_{s}$ are state fixed effects, and $\eta_{i s t}$ is the error term. The second stage of the two-stage least squares (2SLS) regression is given by

$$
Y_{i s t}=\alpha+\gamma_{s}+\rho \hat{V}_{i s}+\beta \mathbf{X}_{i s}+\epsilon_{i s t}
$$

where $Y_{i s t}$ is the outcome measure of interest (e.g., mobility, purchases of protective gear, or COVID-19 infections) and $\hat{V}_{i s}$ are the fitted values from the first stage. If the channel position $Z_{i s}$ is a valid instrument, the 2SLS estimate for $\rho$ captures the local average treatment effect of interest.

All outcomes, as well as the regressor and instrument, are standardized by dividing 
the original values by the respective standard deviations (S.D.). Thus, coefficients can be interpreted as the predicted change in S.D.'s of the outcome for a one-S.D. increase in the channel position. Regression estimates are weighted by local population and standard errors are clustered by state.

For the analysis of shopping for COVID-19-related products, we have data for a relatively small subset of localities (581 zipcodes), and insufficient power in the first stage to produce 2SLS estimates. We therefore produce reduced form estimates where the outcome is regressed directly on the instrument:

$$
Y_{i s t}=\alpha+\gamma_{s}+\delta Z_{i s}+\beta X_{i s}+\eta_{i s}
$$

For the reduced form estimation, the instrument is adjusted so that the magnitudes are comparable with the 2SLS estimation of the other outcomes.

\subsection{Instrument Validity}

There are two key identifying assumptions for the instrumental variables analysis. First, the channel position should be related to viewership (relevance). We provide evidence for instrument relevance in Figure 2, which plots the first-stage relationship (Equation 1). As shown in the graph, a lower FNC channel position is associated with higher FNC viewership. We obtain a sufficiently strong first-stage F-statistic of 12.48 and a coefficient of -0.103 (st. error $=0.029$ ). These statistics imply that a one-standard-deviation increase in FNC position induces a 10 percent decrease in the channel's viewership.

The second identification assumption is that the channel position should not be correlated with other factors, besides viewership, that would influence the observed behavioral or health outcomes. To confirm exogeneity of the instrument, we provide a series of empirical checks. First, we assess whether our instrument is systematically correlated with a jurisdiction's predetermined characteristics, which could be correlated with COVID-19 responses or outcomes. These estimates are reported in Appendix Table A.2. For the main specification, only one out of 11 variables (land area of the county) is significantly correlated with our instrument at a $5 \%$ level; three variables are significant at the $10 \%$ level (above median proportion white, proportion entitled to food stamps, and population density). The presence of unbalanced characteristics could be problematic for the causal identification if such characteristics were also systematically correlated with the outcome of study. In our case, this does not seem to be a problem, as our main results are not significantly affected by the inclusion of these unbalanced characteristics as controls. 
Moreover, we find our results to be robust even when adding these characteristics to the model as polynomials or when interacting them with the main regressor (Appendix Figure A.4).

\subsection{Survey Analysis}

The survey data are analyzed using ordinary least squares regression at the individual respondent level. We regress our outcome measures for COVID-19-related behavior, beliefs, and policy preferences on explanatory variables for cable news viewership. Our detailed data allows us to compare the associations of our outcome measures with watching particular networks and particular shows. All analyses include controls for gender, age, education, race, state fixed effects, and where noted also party identity. Standard errors are clustered by state. See Appendix Section A7 for full details.

\section{Results}

\subsection{Effects on Preventative and Preparatory Measures}

Figure 3 reports the results for our analysis of Fox News viewership on the behavioral response to COVID-19. Each panel shows a coefficient plot with the point estimates and corresponding confidence intervals from separate regressions over time, covering our study period from February 1st through April 30th, 2020. Panels (a) and (b) are daily 2SLS estimates from Equation 2 at the county level. Panel (c) provides weekly reducedform estimates from Equation 3 at the zipcode level (see Methods Section above).

In Panel (a) the outcome is the average time people spend away from home per day. The figure indicates that starting early March, FNC viewers spent relatively more time away from home than non-FNC viewers. Similarly, Panel (b) documents that higher FNC viewership increased the relative daily distance travelled away from as compared to non-FNC viewers. This again suggests that FNC caused it viewers to practice less social distancing. Panel (c) examines the effect on purchases of COVID-19-related products. Holding all else constant, higher FNC exposure is associated with spending relatively less money on these products.

To put these numbers in perspective, they mean that a $10 \%$ increase in FNC viewership (relative to the mean) increased time spent away from home by 30 minutes per day, increased the distance traveled from home by $5.7 \mathrm{~km}$ per day, and decreased COVIDrelated expenditures by $\$ 43$ per grocery store per day. Overall, these patterns are consistent with the notion that on average, FNC viewers were less likely to be alarmed by the impending threat of the virus and to adapt their behavior accordingly. 


\subsection{Effects on COVID-19 Infections and Deaths}

Next, we examine whether FNC viewership has had an impact on the incidence of contracting COVID-19 and on death rates from the virus. As above, we use channel position in the cable box as an instrument for FNC viewership using county-level data. The daily outcome measures the number of new cases per county within the last seven days.

Figure 4 presents the results. We do not find a significant effect of Fox News exposure on infections and deaths. While the coefficients are consistently positive, the large confidence intervals allow for a zero effect of Fox News Channel on these outcomes. Similar results are found when looking at per capita cases and deaths (Appendix Figure A.13) and when extending the study period to May 2020 (Appendix Figure A.14).

\subsection{Robustness Checks for Instrumental Variables Analysis}

We conduct a series of tests to assess the robustness of the results on behavioral responses. First, we re-run all the reduced-form analyses for the mobility outcomes at the zip-code level. This specification allows us to introduce county fixed effects, which control for any time-invariant characteristics at the county level. As seen in Appendix Figure A.3, the effects are actually stronger when using this model.

Next, we assess sensitivity to the presence of specific controls. In Appendix Figure A.5, we estimate an array of reduced-form regressions, each time excluding one of the socio-demographic controls from the benchmark model. The results remain stable throughout. Focusing on the unbalanced characteristics (see Appendix Table A.2), we show that our results are robust to adding polynomials of these variables or interacting them with the main viewership regressor (Appendix Figure A.4). The results are not sensitive to including a baseline control (Appendix Figure A.7).

Next, we perform a number of placebo tests. First, we run the 2SLS regressions but using the mobility data for 2019 rather than the corresponding period in 2020 . Reassuringly, we do not find any effect using this earlier mobility data (Appendix Figure A.10). Second, we test whether our instrument is correlated with the number of seasonal flu casualties in previous years; it is not (Appendix Figure A.15). Third, we extend our analyses to the two other main cable news channels, CNN and MSNBC. We find no effect of viewership of these channels on any of our outcomes of interest (Appendix Figure A.11 and A.12), although the first stage estimation for those channels is also weak. 
Finally, we conduct a permutation test. We regress our benchmark specification 49 times, each time dropping the data for one state. The fact that the estimates remain stable (Appendix Figure A.6) indicates that the reported effects are not driven by any specific outlier state.

\subsection{Survey Analysis of Self-reported Behavior, Attitudes and Beliefs}

To go beyond aggregate behavioral measures and understand how Fox News affects attitudes and beliefs, we now turn to our individual-level survey outcomes. As described in further detail in the Data section, we measure (i) the timing since respondents modified their behavior due to COVID-19, (ii) whether respondents believe that Hydroxychloroquine is an effective drug for treating COVID-19, and (iii) whether respondents prefer the government to prioritize public health risks over harm to the economy.

Figure 5 shows the associations of these outcomes with viewership of the three main cable news channels. The underlying regressions adjust for respondents' sociodemographic characteristics. We find that respondents who watch FNC are slower to adopt behavioral changes in response to COVID-19 (-0.122 on the timing of change index; $\mathrm{p}<0.05$ ), with smaller and insignificant effects from viewership of CNN and MSNBC. FNC viewers are also 12.4 percentage points more likely to believe that Hydroxychloroquine is an effective treatment against COVID-19 (an increase of $46.8 \%$ above the baseline rate; $\mathrm{p}<0.01)$. Finally, $\mathrm{FNC}$ viewers are a lot more likely to prioritize economic activity over protections of public health (a difference of 0.22 , or $65 \%$ above the baseline rate; $\mathrm{p}<0.01)$. For the latter two outcomes, the FNC viewers are significantly different from respondents that prefer other cable news channels.

Together, the survey and behavioral results support the interpretation that FNC viewers are more skeptical of the risk posed by COVID-19 than respondents who do not watch Fox News, and that the FNC effect on self-reported attitudes translated into observable behavior.

\subsection{Analysis of Mechanisms}

A first possible mechanism for these effects is partisanship. Republicans may be more skeptical of COVID-19 (Allcott et al., 2020), and Fox News persuades its viewers to become Republicans (DellaVigna and Kaplan, 2007; Martin and Yurukoglu, 2017). This mechanism would suggest that we are estimating a Republican, rather than Fox News, effect. 
This mechanism, by itself, cannot explain our results. If partisanship were the main driver of the results, we would expect that the effects would not hold when we control for the respondents' partisan preferences. For both the observational outcomes and survey responses, that is not the case. When we include controls for viewers' partisan leanings, the results all hold (Appendix Table A.9).

There are two other key mechanisms that we explore. On the second mechanism, the effects could be a result of cumulative watching Fox News coverage. Anecdotal and statistical research has documented that, in general, Fox News is antithetical to science and to the scientific establishment (Feldman et al., 2012; Huertas and Kriegsman, 2014; Hmielowski et al., 2014). This long-run effect on views toward science, in turn, may have led FNC viewers to shun public health instructions by officials and public health experts.

The third potential mechanism we explore is the influence of FNC's specific messaging on coronavirus. That is, the differences in COVID-related attitudes and behavior may reflect FNC's coverage of the pandemic itself. The specific messaging from programs that promoted a skeptical stance on the threat posed by the virus would then directly persuade viewers and lead to lower adherence to social distancing among them.

We investigate mechanisms 2 and 3 as follows. Note that if pre-existing differences in, or cumulative effects on, attitudes were driving the results (mechanism 2), we would expect that COVID-19 attitudes and behaviors would not vary across viewers of different shows. That is, different Fox News shows that were similar in their political stance before the pandemic would have the same effect on viewer's behavior with respect to COVID-19, independent of differences in their reporting on the virus. We can test this implication using our survey data, where we asked FNC respondents which shows they usually watched. Specifically, we compare viewers that watch Hannity, Tucker Carlson Tonight, and Fox \& Friends. While all three shows have a strong conservative political slant, they strongly differed in their coverage of the threat posed by COVID-19. Whereas Hannity had been minimizing the risks, Tucker Carlson had stressed the potential for a pandemic and its harmful impact (Bursztyn et al., 2020). The editorial line in Fox \& Friends was in between the other two programs.

The results of this comparison are reported in Figure 6. Each panel shows the differences in the self-reported behavioral outcome (adopting of social-distancing measures), for a different subset of survey respondents (full sample, Republicans, Republicans who regularly watch FNC, and Conservative Republicans). The panels show that Fox News 
viewers of the three shows responded very differently to COVID-19. Hannity viewers were far less likely to adapt social-distancing behaviors than those who did not watch Hannity (-0.33, $\mathrm{p}=0.001$, about one half a standard deviation). In contrast, with Fox \& Friends or Tucker Carlson Tonight there is no difference. Subsetting the sample to Republicans, or to Republicans who are conservative and/or regular viewers of Fox, does not change the sign or magnitude of the Hannity effect. Indeed, in some of these subsets, viewers of Tucker Carlson Tonight were somewhat more likely to adopt social-distancing measures than non-viewers (albeit only marginally statistically significant). ${ }^{1}$

Overall, this evidence provides support for mechanism 3. COVID-19-specific messaging is driving at least part of the attitudinal and behavioral responses of FNC viewers. The longer-term effects of Republican partisanship (mechanism 1) and general skepticism toward scientists and elites (mechanism 2) likely added to this effect.

\section{Discussion}

Our instrumental variable analysis provides evidence of the substantial impact media coverage has on viewers' beliefs, preferences, and behavior in the context of COVID19. We find that Fox News viewership led to lower compliance with social distancing measures and lower investment in preparedness. However, we find no evidence that these shifts in behavior affected health outcomes such as infections or mortality. Our survey data suggests that the impact of Fox News is not merely related to the network's longstanding partisan stance or skepticism toward scientific evidence. Rather, the specific messaging of shows with regard to the threat posed by COVID-19 is key in explaining the observed behavioral changes.

Crucially, this impact of FNC's coverage took place in circumstances in which viewers had a strong vested interest in obtaining and adhering to accurate information. Our study questions the notion that the "marketplace of ideas" - a competitive media environment-will weed out misinformation. Rather, widening political polarization poses the threat that biased media coverage of key developments, even those related to a major public health crisis, can have lasting consequences for the beliefs and behaviors

\footnotetext{
${ }^{1}$ Appendix Table A.10 reports patterns for the other two survey outcomes (beliefs regarding effectiveness of Hydroxcloroquine, preferences regarding the policy prioritization of the economy versus public health). The results with respect to those two outcomes are very similar when analyzing the full sample, yet drop below statistical significance when restricting the analysis only to Republicans and conservatives.
} 
of its audience. 


\section{Figures}

Figure 1: Divergent Narratives on Fox News Channel: Skeptical COVID-19 Memes
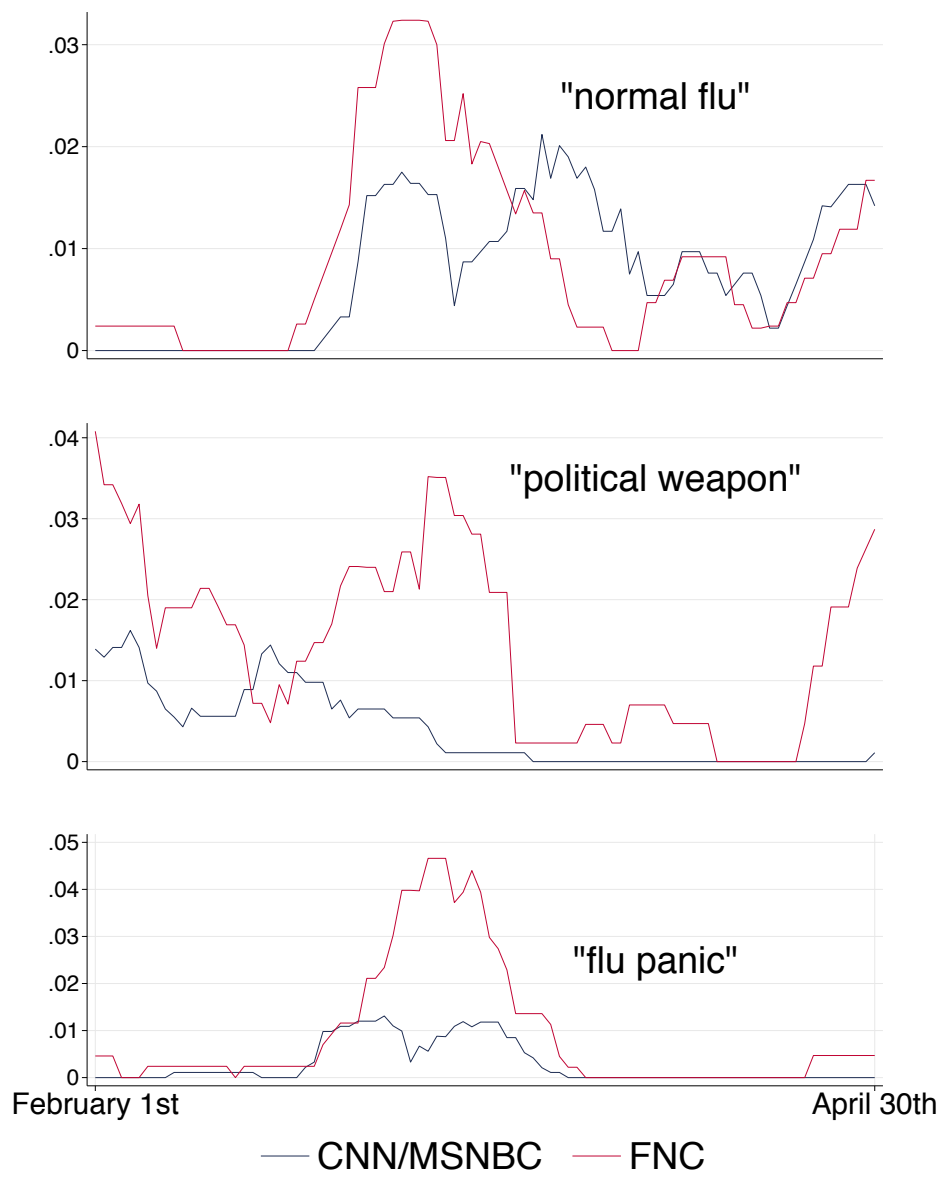

Notes: Smoothed phrase frequencies from Fox News (red series) and CNN/MSNBC (blue series) for Feb 1st through April 30th, 2020, as described in Appendix Section A2. 
Figure 2: Instrument Relevance

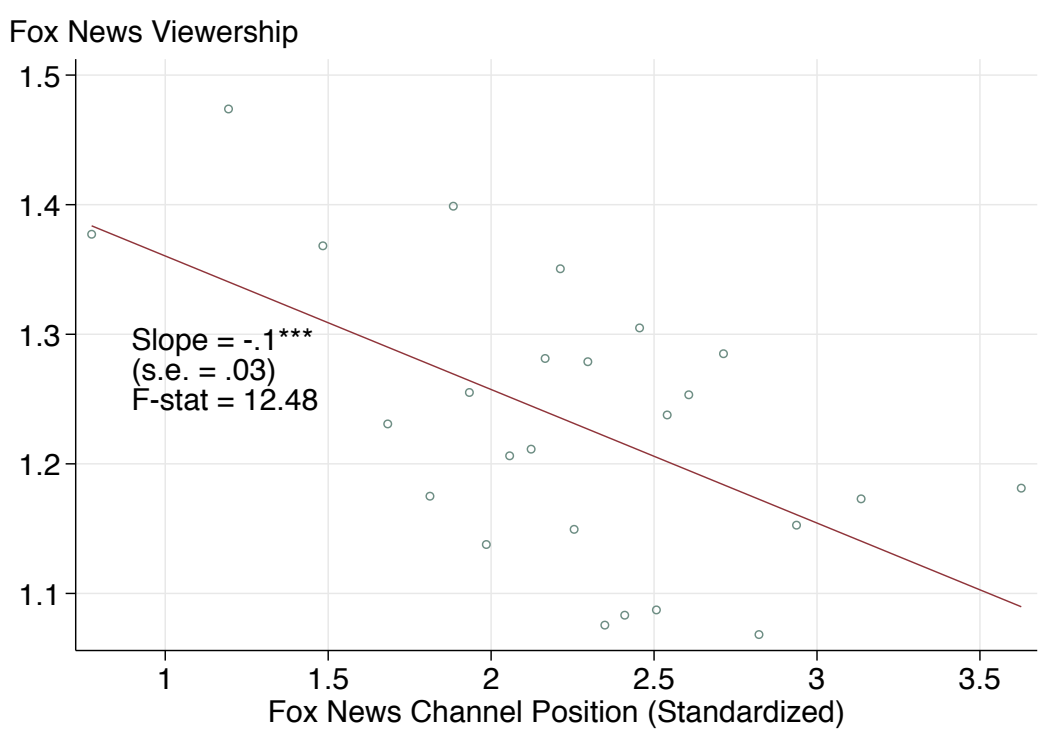

Notes: Binscatter and statistics from first stage (Equation 1) regressing FNC viewership on FNC channel position. $\mathrm{N}=3,033$ counties, 49 states. 
Figure 3: Fox News Effect on Mobility and COVID-19 Outcomes

(a) Effect on Time Outside Home (2SLS)

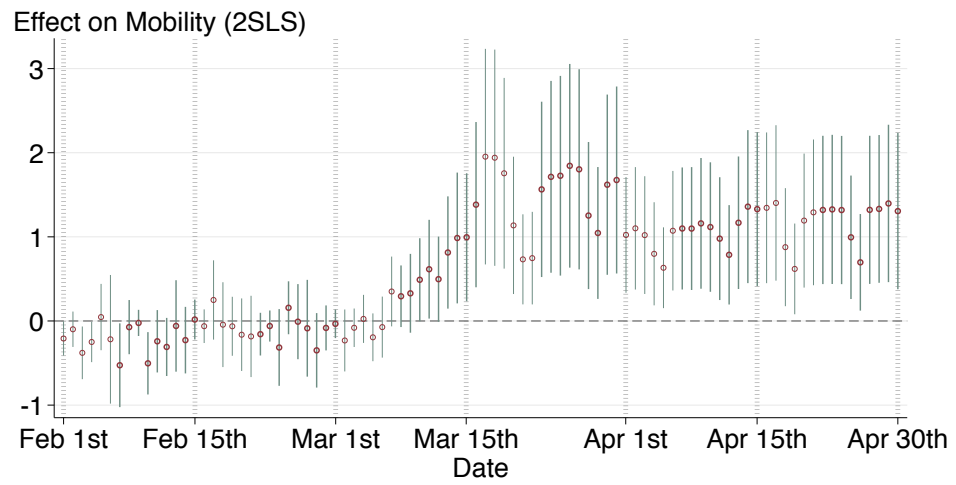

(b) Effect on Distance from Home (2SLS)

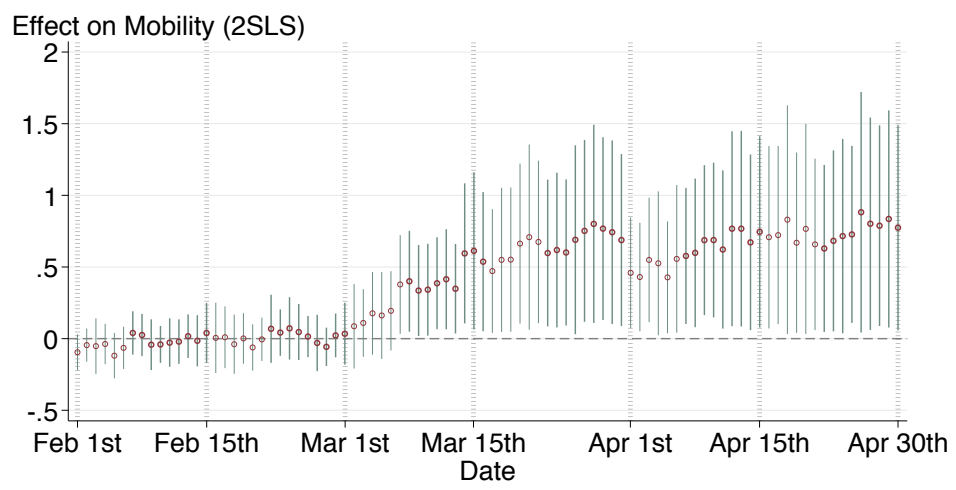

(c) Effect on Weekly COVID-Related Purchases (RF)

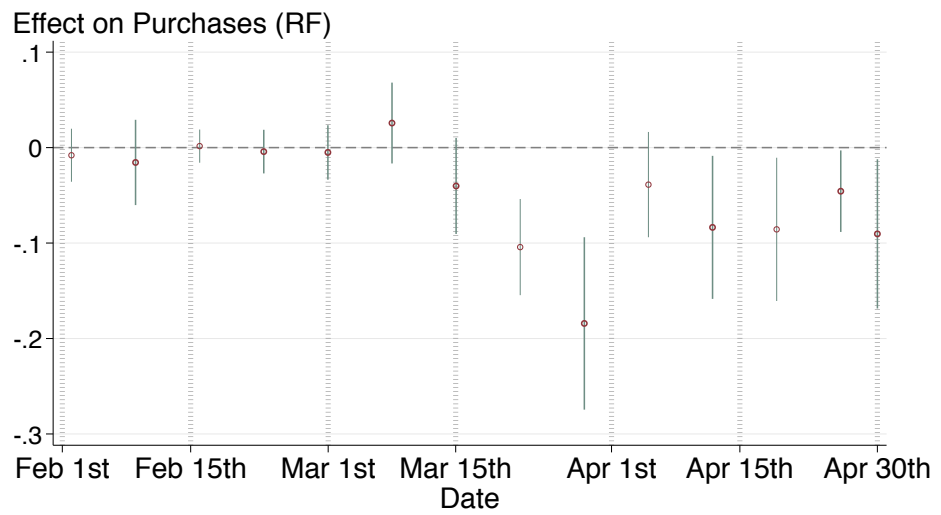

Notes: Each panel shows a series of coefficient plots with $95 \%$ confidence intervals from regressions of the effect of Fox News Channel viewership on the stated outcome. Panels (a) and (b): Two-stageleast squares (2SLS) regressions for daily outcomes, with standardized viewership instrumented with channel position ( $N=3033$ counties, 49 states). Panel (c): Reduced form (RF) regressions with weekly outcome regressed on standardized channel position $(N=581$ zip codes, 10 states $)$. Regressions include demographic and cable-system controls, described in Data. Standard errors clustered by state. 
Figure 4: Fox News Effect on COVID-19 Infections and Deaths

(a) Number of COVID-19 Infections (7-day difference)

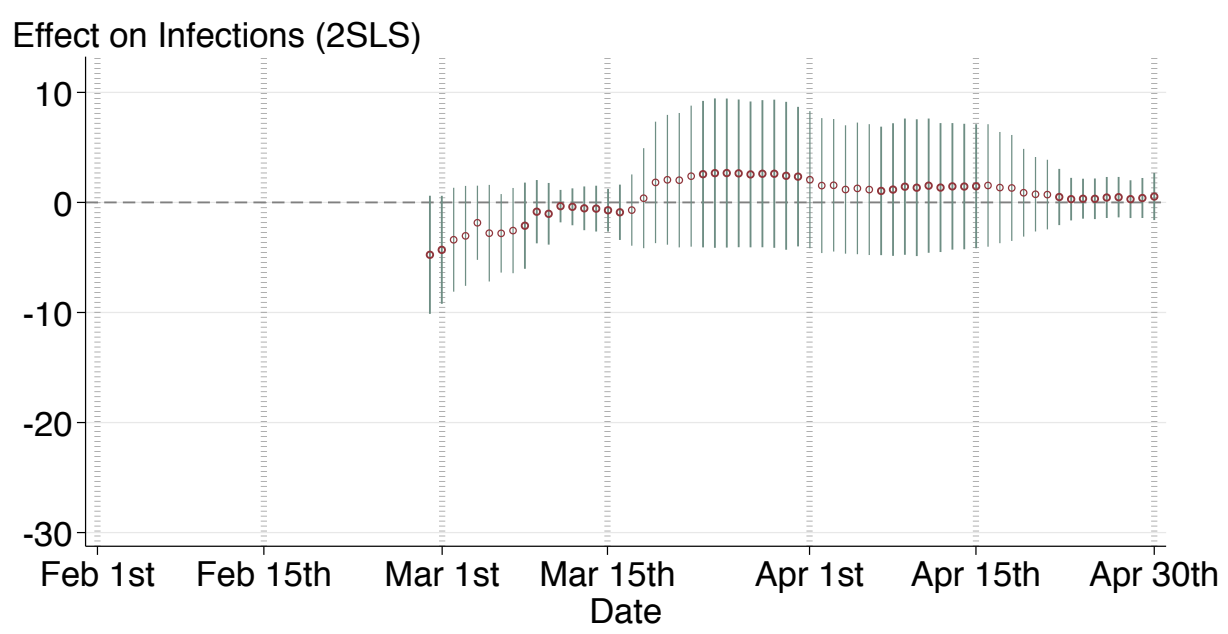

(b) Number of Deaths attributed to COVID-19 (7-day difference)

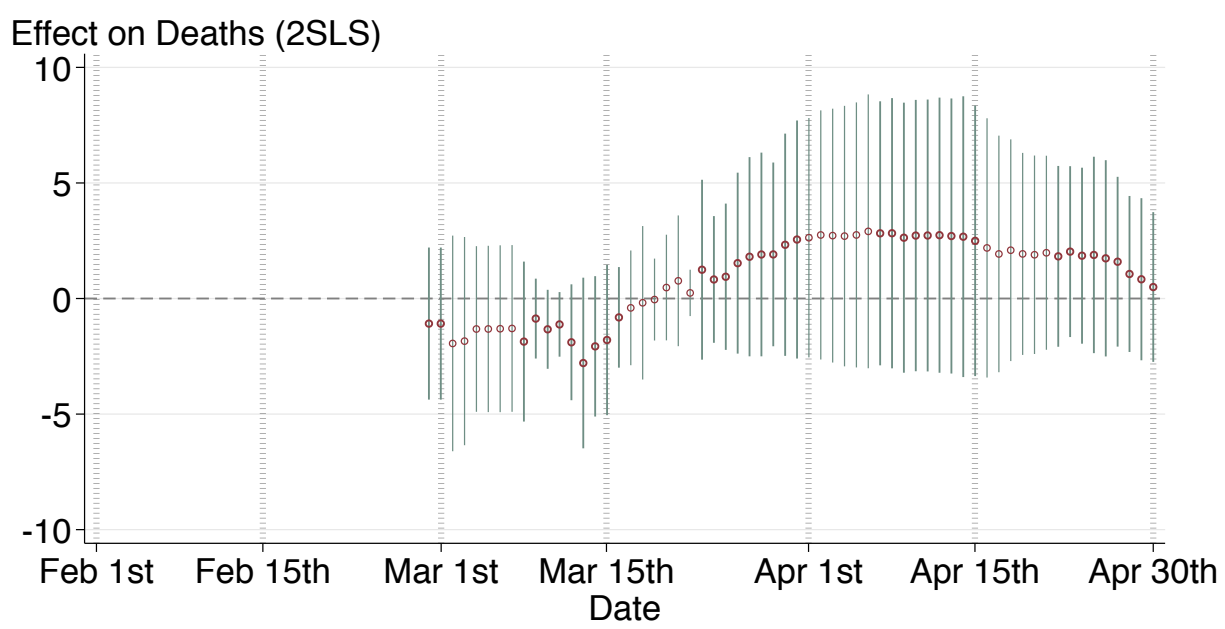

Notes: Each panel in this figure shows a series of coefficient plots and $95 \%$ confidence intervals for daily 2SLS regressions of the effect of Fox News Channel standardized viewership on new cases and deaths in the previous seven days. 
Figure 5: COVID-19 Related Behavior, Beliefs and Preferences, by Channel Viewership

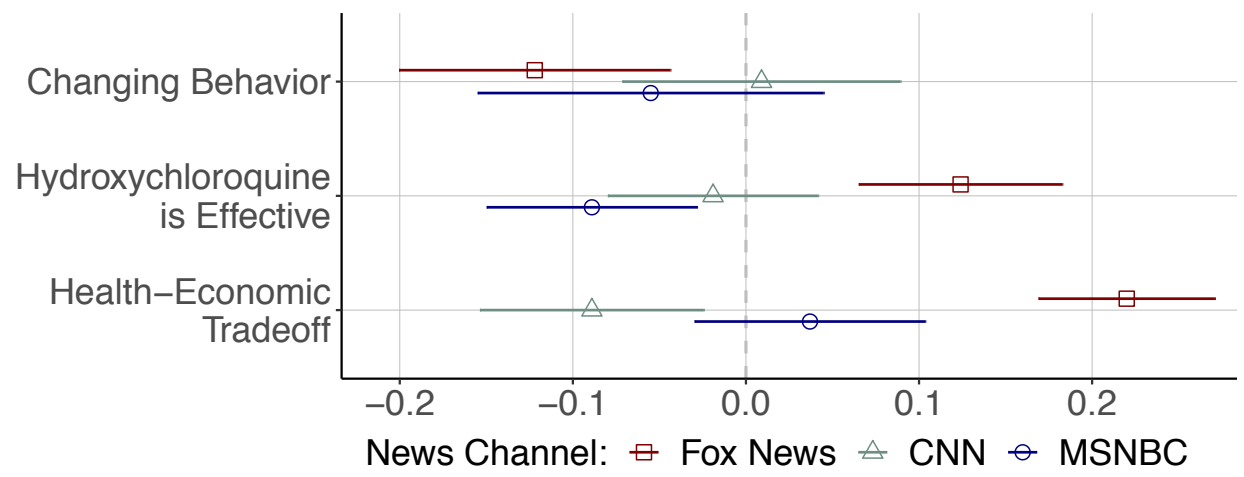

Notes: Coefficient plots for regressions of stated survey outcome on news channel viewership, controlling for individual covariates and clustering standard errors by state. Outcomes are self-reported changing of behavior, belief in effectiveness of Hydroxcloroquine as a COVID-19 treatment, and a view on whether government should focus more on public health relative to economic harms. See Appendix Section A7 for full details.

Figure 6: Effects on COVID-19 Responses, by Fox News Program
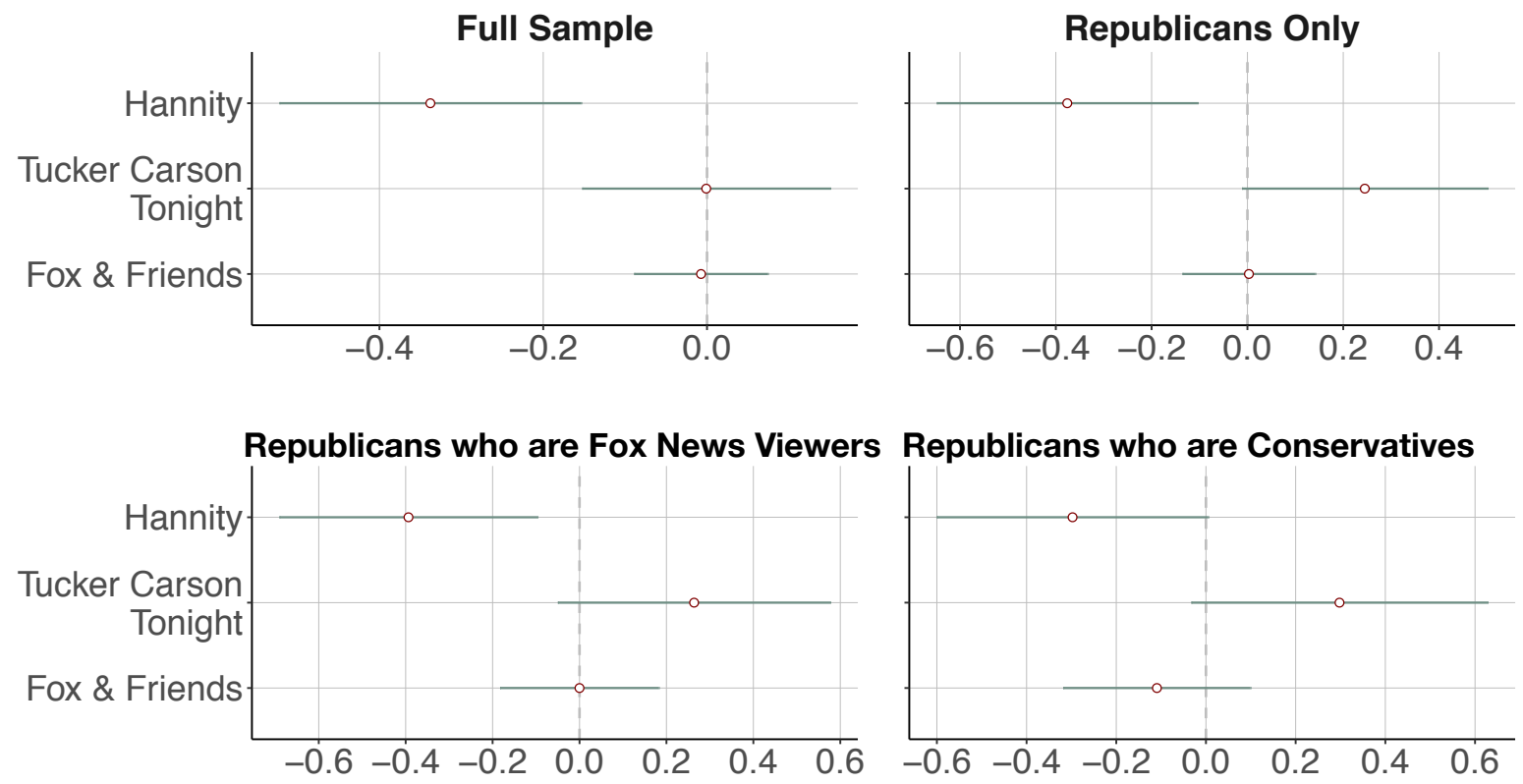

Notes: Coefficient plots for regressions of self-reported social distancing measures on viewership of the associated shows, controlling for individual covariates and clustering standard errors by state. Lower values mean less social distancing. See text for full details. 


\section{References}

Abutaleb, Y., Dawsey, J., Nakashima, E., Miller, G., 2020. The u.s. was beset by denial and dysfunction as the coronavirus raged. The Washington Post, 4 March .

Allcott, H., Boxell, L., Conway, J., Gentzkow, M., Thaler, M., Yang, D.Y., 2020. Polarization and public health: Partisan differences in social distancing during covid-19. Available at SSRN 3570274 .

Badger, E., Quealy, K., 2020. Red vs. blue on coronavirus concern: The gap is still big but closing. The New York Times, March 21 .

Bursztyn, L., Rao, A., Roth, C., Yanagizawa-Drott, D., 2020. Misinformation during a pandemic. University of Chicago, Becker Friedman Institute for Economics Working Paper .

Coppock, A., McClellan, O.A., 2019. Validating the demographic, political, psychological, and experimental results obtained from a new source of online survey respondents. Research \& Politics 6, 2053168018822174.

DellaVigna, S., Kaplan, E., 2007. The fox news effect: Media bias and voting. The Quarterly Journal of Economics 122, 1187-1234.

DellaVigna, S., La Ferrara, E., 2015. Economic and social impacts of the media, in: Handbook of media economics. Elsevier. volume 1, pp. 723-768.

Dong, E., Du, H., Gardner, L., 2020. An interactive web-based dashboard to track covid-19 in real time. The Lancet infectious diseases 20, 533-534.

Egorov, G., Enikolopov, R., Makarin, A., Petrova, M., 2020. Divided We Stay Home: Social Distancing and Ethnic Diversity. Working Paper 27277. National Bureau of Economic Research. URL: http: //www . nber .org/papers/w27277, doi:10 .3386/w27277.

Feldman, L., Maibach, E.W., Roser-Renouf, C., Leiserowitz, A., 2012. Climate on cable: The nature and impact of global warming coverage on fox news, cnn, and msnbc. The International Journal of Press/Politics 17, 3-31.

Galletta, S., Ash, E., 2019. How cable news reshaped local government. Available at SSRN 3370908 .

Hmielowski, J.D., Feldman, L., Myers, T.A., Leiserowitz, A., Maibach, E., 2014. An attack on science? media use, trust in scientists, and perceptions of global warming. Public Understanding of Science 23, 866-883.

Huertas, A., Adler, D., et al., . Is news corp. failing science? . 
Huertas, A., Kriegsman, R., 2014. Science or spin? A report by the Union of concerned scientists, Washington, DC 12.

Martin, G.J., Yurukoglu, A., 2017. Bias in cable news: Persuasion and polarization. American Economic Review 107, 2565-99.

Peters, J.W., Grynbaum, M.M., 2020. How right-wing pundits are covering coronavirus. The New York Times, March 11 .

Simonov, A., Sacher, S.K., Dubé, J.P.H., Biswas, S., 2020. The persuasive effect of fox news: non-compliance with social distancing during the covid-19 pandemic. Technical Report. National Bureau of Economic Research. 


\section{ONLINE APPENDIX}

\section{A1. Cable News Background}

The U.S. cable news market is dominated by three channels: CNN, introduced in 1980, Fox News Channel (FNC) and MSNBC (both introduced in 1996). Each channel provides program schedules and content that are the same nationwide, but their availability has varied across localities. This is due to the geographically fragmented market for cable providers. Most of the time, national media producers have to reach separate agreements with local cable companies in order to make their channel available to the final users. As these procedures might start and end at different times, the result is that channel accessibility has varied significantly over space and time (DellaVigna and Kaplan, 2007).

One consequence of this variation is that the lineup positions assigned to each channel in the cable box were a function of the time in which the channel was added to the local cable system, as new channels were typically positioned sequentially. It was also common for local cable providers to place channels within a similar genre in adjacent or very close positions. Notably, channel positions are generally stable over time to avoid confusing customers searching for the channel. Therefore, the numerical order of the different channels varies across the different cable systems.

Martin and Yurukoglu (2017) provide further detail on the process by which channel positions are assigned.

\section{A2. Variation in Cable News Coverage}

Figure 1 was produced using the GDELT Television Comparer API (accessible at https://api.gdeltproject.org/api/v2/summary/summary). The GDELT API is a flexible news search interface, where one can specify specific networks and specific days. It provides statistics on relative frequencies for user-provided search queries. To produce our graphs, we searched the Television News Archive for the stated query, limiting to the stated networks, for the dates Feb 1st through April 30, 2020. We used 10-lags as a smoothing parameter.

\section{A3. Description of data sources}

This appendix provides additional information about the data for the observational analysis. Summary statistics are reported in Table A.1. 
Table A.1: Summary Statistics: Observational Data

\begin{tabular}{|c|c|c|c|c|c|}
\hline Variable & Mean & Std. Dev. & Min & $\operatorname{Max}$ & $\mathrm{N}$ \\
\hline \multicolumn{6}{|l|}{ News channels (county level) } \\
\hline Ratings \% Fox News 2020 & 1.656 & 2.345 & 0 & 67.400 & 3,033 \\
\hline Ratings \% MSNBC 2020 & 0.377 & 0.518 & 0 & 11.9 & 3,033 \\
\hline Ratings \% CNN 2020 & 0.538 & 0.835 & 0 & 26.4 & 3,033 \\
\hline Fox News channel position 2016 & 74.303 & 38.389 & 31.43 & 140.109 & 3,033 \\
\hline MSNBC channel position 2016 & 82.922 & 42.89 & 34.946 & 158.798 & 2,996 \\
\hline CNN channel position 2016 & 65.197 & 37.359 & 24.05 & 129.149 & 3,031 \\
\hline \multicolumn{6}{|l|}{ News channels (zip code level) } \\
\hline Fox News channel position 2016 & 79.334 & 40.794 & 30 & 147.667 & 27,288 \\
\hline CNN channel position 2016 & 70.017 & 39.915 & 24 & 136 & 27,288 \\
\hline MSNBC channel position 2016 & 90.711 & 52.328 & 34 & 199 & 27,288 \\
\hline \multicolumn{6}{|c|}{ News channels (zip code level-grocery) } \\
\hline Fox News channel position $2016^{3}$ & 87.588 & 33.388 & 30 & 147.667 & 581 \\
\hline CNN channel position 2016 & 78.570 & 33.19 & 24 & 136 & 581 \\
\hline MSNBC channel position 2016 & 98.75 & 44.032 & 34 & 199 & 581 \\
\hline \multicolumn{6}{|l|}{ Demographic (county level) } \\
\hline Population & $100,672.477$ & $317,893.337$ & 80 & $9,818,535$ & 3,033 \\
\hline Population density & 188.094 & 920.453 & 0.129 & $33,886.035$ & 3,033 \\
\hline Area & 510.295 & 664.63 & 1.553 & $9,309.787$ & 3,033 \\
\hline Age imbalance & 1.702 & 0.226 & 1.09 & 4 & 3,033 \\
\hline Food stamps & 0.126 & 0.059 & 0 & 0.431 & 3,033 \\
\hline Median republican 2016 & 0.5 & 0.5 & 0 & 1 & 3,033 \\
\hline Median republican 2012 & 0.5 & 0.5 & 0 & 1 & 3,033 \\
\hline No high school & 0.163 & 0.071 & 0.014 & 0.537 & 3,033 \\
\hline College & 0.192 & 0.085 & 0.054 & 0.706 & 3,033 \\
\hline Black pop ab. median & 0.5 & 0.5 & 0 & 1 & 3,033 \\
\hline White pop ab. median & 0.5 & 0.5 & 0 & 1 & 3,033 \\
\hline Male & 0.499 & 0.021 & 0.438 & 0.719 & 3,033 \\
\hline \multicolumn{6}{|l|}{ Demographic (zip code level) } \\
\hline Population & $11,144.397$ & $14,390.684$ & 4 & 11,3916 & 27,288 \\
\hline Population density & 547.232 & $1,963.413$ & 0.011 & $57,231.166$ & 27,288 \\
\hline Area & 193.707 & 436.68 & 0.009 & $23,599.013$ & 27,288 \\
\hline Age imbalance & 1.841 & 1.085 & 0.021 & 130.5 & 27,288 \\
\hline Food stamps & 0.11 & 0.095 & 0 & 1 & 27,288 \\
\hline No high school & 0.149 & 0.107 & 0 & 1 & 27,288 \\
\hline College & 0.225 & 0.16 & 0 & 1 & 27,288 \\
\hline Black pop ab. median & 0.424 & 0.494 & 0 & 1 & 27,288 \\
\hline White pop ab. median & 0.561 & 0.496 & 0 & 1 & 27,288 \\
\hline Male & 0.499 & 0.034 & 0 & 0.995 & 27,288 \\
\hline \multicolumn{6}{|c|}{ Demographic (zip code level - grocery) } \\
\hline Population & $25,924.983$ & $13,368.793$ & 2,175 & 72,248 & 581 \\
\hline Population density & 691.569 & 838.949 & 8.092 & $4,757.85$ & 581 \\
\hline Area & 161.797 & 222.673 & 0.977 & $1,679.866$ & 581 \\
\hline Age imbalance & 1.811 & 0.401 & 0.531 & 6.729 & 581 \\
\hline Food stamps & 0.115 & 0.071 & 0.005 & 0.416 & 581 \\
\hline No high school & 0.145 & 0.08 & 0.015 & 0.622 & 581 \\
\hline College & 0.258 & 0.135 & 0.037 & 0.76 & 581 \\
\hline White pop ab. median & 0.251 & 0.434 & 0 & 1 & 581 \\
\hline Black pop ab. median & 0.885 & 0.32 & 0 & 1 & 581 \\
\hline Male & 0.487 & 0.023 & 0.425 & 0.712 & 581 \\
\hline
\end{tabular}




\section{Channel positions}

Channel positions for FNC, MSNBC and CNN come from the Nielsen FOCUS database, which reports channel lineups of all U.S. local broadcast systems, with information about the area served by the system at the zip-code level. We use channel positions from 2016, the latest year for which we have access. Similar to Galletta and Ash (2019), we aggregate the data at the county level, by averaging zip-code-level channel positions with weighting by population size. To address the presence of outlier channels, we winsorize the variables at the top and bottom deciles. Throughout the analysis the channel position is inverted (taking the negative of the position), for representation purposes and standardized diving by its standard deviation for easier understanding of the magnitude of the effects.

\section{Nielsen 2020 ratings}

Television viewership by county of FNC, MSNBC and CNN, is provided by Nielsen. The measure is "ratings," which is proportional to the number of minutes that each household tuned in to each specific channel during the months of January and February 2020. We standardize the viewership throughout the paper by its standard deviation for all networks. The ratings of the channels are only available at the County level are therefore not included in the Zipcode level analysis. Some counties in the raw data were split in parts (e.g. North County-A, East County-A), and were aggregated together by simple average.

\section{Coronavirus cases and deaths}

The confirmed COVID-19-related number of cases and number of deaths are based on the COVID-19 Dashboard published by the Center for Systems Science and Engineering (CSSE) at Johns Hopkins University (Dong et al., 2020). CSSE aggregates information from the World Health Organization, the Center for Disease Control, state health departments, and other agencies. Information is reported daily at the county level. When cases and deaths are missing for a county for a given day, they are coded as zero. Deaths and cases per capita are created as deaths and cases divided by population times 1000 . Cases and deaths are extremely sparse for the dates before the ones reported in the graphs, for representation purposes those estimates are not reported as they would make the graphs unreadable. 


\section{Mobility}

Safegraph ${ }^{2}$ provides information about individuals' mobility based on mobile phone device locations. The data is reported at the Census Block Group level (CBG), a small area with between 600 and 1300 people. For each device, the "home" is determined by the modal nighttime location for the device over the reporting period. ${ }^{3}$ In the analysis we include mobility variables standardized by their standard deviation, this is done at the Zipcode level before aggregating at the County level. ${ }^{4}$

We observe three mobility outcomes at the daily level. First, distance from home is the median distance traveled from home that day for households in that CBG (excluding any distances of 0). Second, Time outside home is the median of observed minutes outside of home across the day (whether or not these were contiguous) for each device in the sample. Third, Full-time work is defined as the proportion of devices that spend six hours outside of the home during the period of $8 \mathrm{am}-6 \mathrm{pm}$ in local time. We include in appendix the results for part-time workers, defined as the proportion of devices that spend three to six hours outside of the home during work hours, this does not include any device that spent 6 or more hours at a location other than home. And the number of devices at home: defined as the number of devices that didn't leave home during the period, out of the device_count.

For all outcomes other than the proportion of devices, Safegraph reports that first the median or the number of minutes for each device is calculated, then the median across all of the devices", where device_count is the number of devices in the panel for the day whose registered home is in the census_block_group. Home is defined as "the common nighttime location for the device over a 6 week period where nighttime is $6 \mathrm{pm}$ - 7 am". Census_block_groups with less than 5 devices are not included.

We report two notes by Safegraph concerning some of the metrics involved in the analysis: "To preserve privacy, we apply differential privacy to all of the device count metrics other than the device_count. This may cause the exact sum of devices to not equal device_count, especially for sparsely populated origin_census_block_group. Differential

\footnotetext{
${ }^{2}$ Our data on level of mobility is obtained from SafeGraph, a data company that aggregates anonymized location data from numerous applications. Data at https://docs.safegraph.com/docs/social-distancing-metrics

${ }^{3}$ To enhance privacy, SafeGraph excludes census block group information if fewer than five devices visited an establishment in a month from a given census block.

${ }^{4}$ In the regressions mobility sample at the zipcode level we include 27288 zipcodes and 3033 counties at the county level.
} 
privacy is applied to all of the following columns: completely_home_device_count, part_time_work_behavior_devices, full_time_work_behavior_devices.." and "Why do the counts seem low for part_time_work_behavior_devices, full_time_work_behavior_devices, and delivery_behavior_devices seem low? These columns are relatively new and experimental for SafeGraph, and there is reason to expect these columns to under-report as a fraction of device_count. We generally do not collect data for devices throughout the day, so only a subset of devices have enough data to be eligible for columns like full time work and delivery behavior. However, device_count has no requirement for sufficient data, so there is a selection bias for devices to be included in the *_behavior_devices columns. We expect that these counts are directionally correct, and valid for looking at trends over time, but not as reliable for estimating exact percentages as a fraction of device_count". ${ }^{5}$

For further information on the mobility data: https://docs. safegraph.com/docs/ social \protect \discretionary $\backslash$ char $\backslash$ hyphenchar $\backslash$ font $\}\{\}\{\}$ distancing-metrics .

The baseline for these measures is created by us as follows: for the last 28 days ( 4 weeks, 4 dates per day of the week) of January 2020, we take the average of the four days corresponding to the same day of the week. For example, for Thursday April 30 2020, we calculate the baseline as the average of the last four Thursdays of January 2020.

CBG's are linked to counties already by the census. We link the CBGs to zipcodes using the University of Missouri's Geocorr tool. ${ }^{6}$

\section{Shopping}

Decadata ${ }^{7}$ provides transaction-level data on Covid-19-related purchases. Transactions come from a set of around 1200 stores for 581 zipcodes in 10 states. The data include net and gross price and quantity sold for the following products: cleaning products, face masks, hand sanitizer, face tissues, and toilet paper. Data are aggregated by zipcode, weighting by 2010 US Census population. For these products we create the total expenditure as the quantity purchased times the net price. We include as a baseline control the average expenditure for the Zipcode in January 2020. Counties in the sample with missing quantity of purchases on a given date ar put to 0 if the county is

\footnotetext{
${ }^{5}$ https://docs.google.com/document/d/1h-pkpIZWeynF3_BcylRmgeWS7282kIUGoM0TSSIUhgM/ edit\#

${ }^{6}$ http://mcdc.missouri.edu/applications/geocorr2018.html

${ }^{7}$ http://decadata.io/\#data
} 
in sample. ${ }^{8}$. Data are aggregated by week from Monday to Sunday.

\section{Demographics and Politics}

The data on local demographics come from the 2010 U.S. Census. The benchmark specification includes the following set of controls, corresponding to the county or zipcode level depending on the regression: population, population density, land area, working-age share of population aged 20-69 over other ages, proportion eligible for food stamps, proportion with no high school attended, proportion who attended college, a dummy for above-median black population share, a dummy for above-median white population share, and proportion male gender. Data on political attitudes includes dummies for above-median Republican vote share from the 2012 and 2016 presidential elections, these data are only available and used in the County level regressions.

\footnotetext{
${ }^{8}$ We define a county as in sample if data for any product are available for at least two days.
} 


\section{A4. Details on IV Methods}

This section reports the balance checks of our instrumental variable Fox News Channel position. In addition to the first-stage estimation in Figure 2, we further include in the first-stage specification the day of the week baseline used for the mobility sample. Coefficients and standard errors are virtually identical, with a lowest F-statistic of 9.48 for one day of the week.

Table A.2: Balance Checks on Channel Position Instrument

\begin{tabular}{lcc}
\hline Variable & Coefficient & st. errors \\
\hline Panel A. State FE (county level) main sample & & \\
Age imbalance & 0.0253 & $(0.0271)$ \\
Food stamps & 0.0780 & $(0.0391)$ \\
Collage & -0.0592 & $(0.0380)$ \\
Male & -0.0260 & $(0.0192)$ \\
No high school & -0.0306 & $(0.0261)$ \\
Black pop ab. median & -0.0635 & $(0.0477)$ \\
White pop ab. median & 0.0504 & $(0.0295)$ \\
Median republican 2016 & 0.0180 & $(0.0272)$ \\
Median republican 2012 & 0.0270 & $(0.0258)$ \\
Population density & -0.574 & $(0.296)$ \\
Area & $0.0383^{*}$ & $(0.0155)$ \\
& & \\
Panel B. County FE (zipcode level) main sample & & \\
Age imbalance & -0.00967 & $(0.0152)$ \\
Food stamps & 0.0131 & $(0.0167)$ \\
Collage & 0.00246 & $(0.0162)$ \\
Male & 0.00946 & $(0.0105)$ \\
No high school & -0.0193 & $(0.0101)$ \\
Black pop ab. median & -0.00242 & $(0.0136)$ \\
White pop ab. median & -0.00744 & $(0.0116)$ \\
Population density & -0.150 & $(0.0909)$ \\
Area & $0.0141^{*}$ & $(0.00585)$ \\
Panel C. State FE (zip level) grocery sample & & \\
Age imbalance & & \\
Food stamps & 0.0151 & $(0.00769)$ \\
Collage & -0.0137 & $(0.0284)$ \\
Male & 0.0644 & $(0.0342)$ \\
No high school & $-0.0353^{*}$ & $(0.0127)$ \\
Black pop ab. median & $0.0466^{*}$ & $(0.0147)$ \\
White pop ab. median & 0.00163 & $(0.0158)$ \\
Population density & -0.0212 & $(0.0372)$ \\
Area & -0.0110 & $(0.00701)$ \\
& 0.0339 & $(0.0191)$ \\
\hline
\end{tabular}

Notes. We report here a correlation check between our instrument - Fox News Channel position - and local characteristics (see description in Appendix A3). Each row is from a regression similar to the reduced form (Equation 3), with the specified charac- 
teristic as the outcome and other controls still on the right-hand side. Panel A provides balance checks for the main specification with county-level data, State FE's, and clustering by state. Panel B shows balances at the Zipcode level for the mobility sample, while Panel $\mathrm{C}$ does so for the Covid-related purchases sample. Weighting is done by county (panel A) or zipcode population (panels B and C). Political Elections controls and CNN and MSNBC viewership are not available, and so not included, at the Zipcode level. Coefficients are standardized by the standard deviation. 


\section{A5. Additional Behavioral-Response Results}

This section reports the additional results for behavioral response outcomes. In the main text, we interpreted the coefficients as follows. We took the average coefficients for March 15th through March 31st. We then rescaled the average coefficient based on the mean and standard deviation of the outcome and of FNC ratings to produce interpretable quantities.

For the corona-related purchases estimates, we use the two weeks from March 16th29th. Because the estimates are from the reduced form, we produce interpretable coefficients by assuming the same first stage effect as with the other mobility measures. The coefficient is at the zip code level, so we divided by the number of stores per zip code (2.06) to get a store-level estimate. 
Figure A.1: Effect on Mobility Outcomes: OLS

(a) Distance from home - FXNC

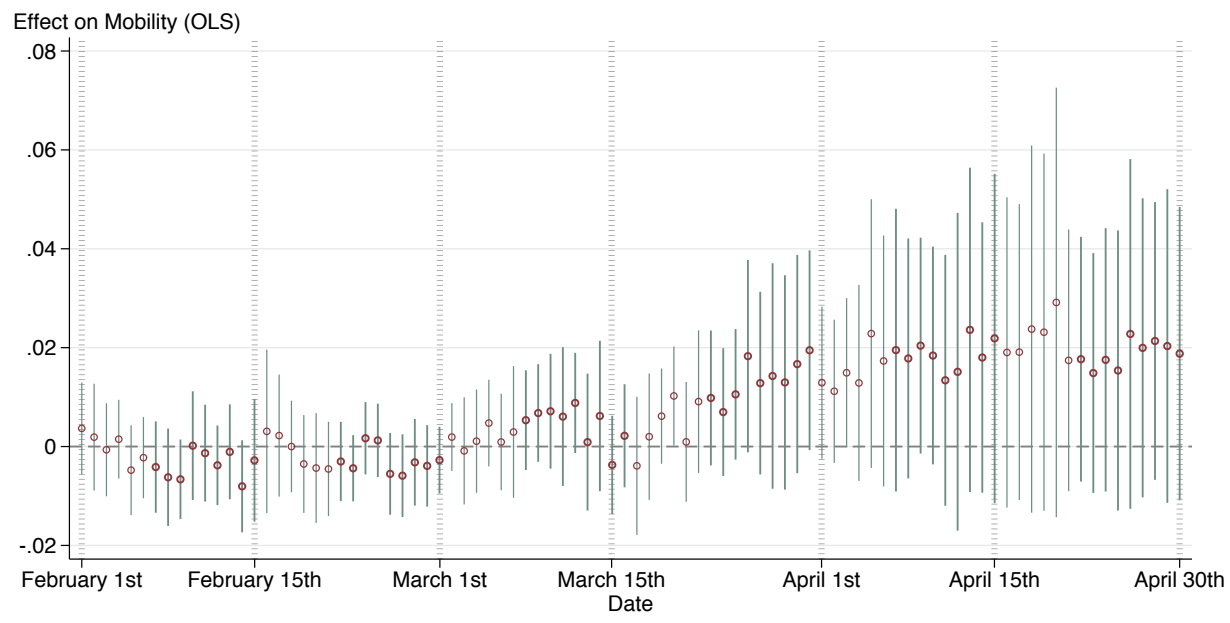

(b) Time outside home - FXNC

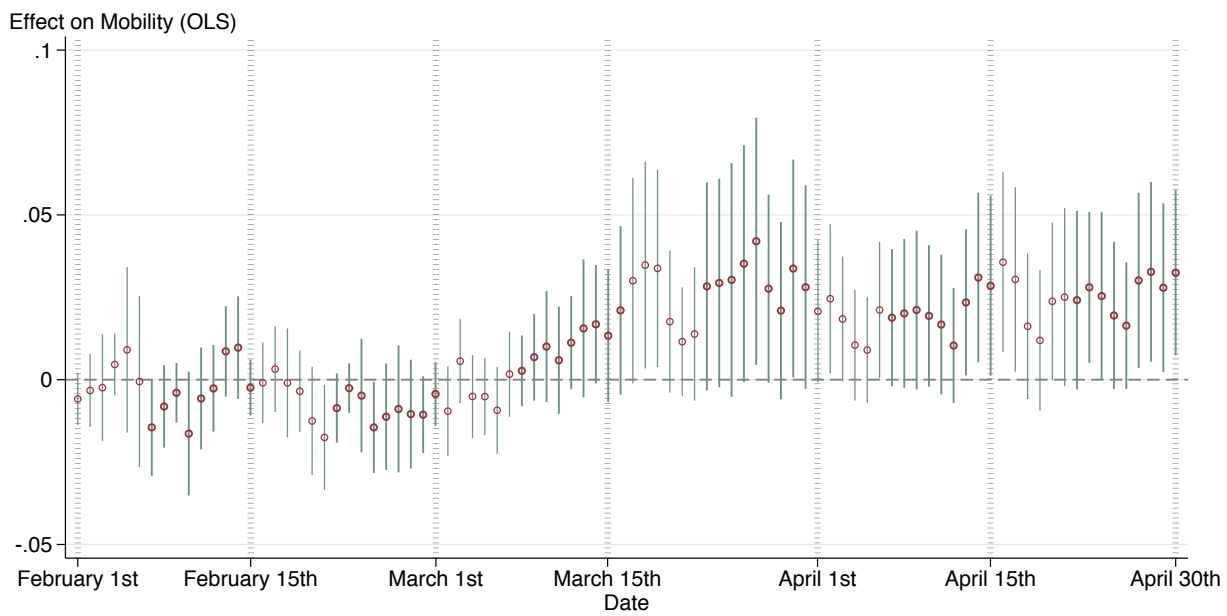

Notes: Ordinary least Squares (OLS) regression results for the effect of FNC on mobility outcomes (Equation 2), analogous to 2SLS results in Figure 3. 
Figure A.2: Effect on Mobility Outcomes: Reduced Form

(a) Distance from home - FXNC

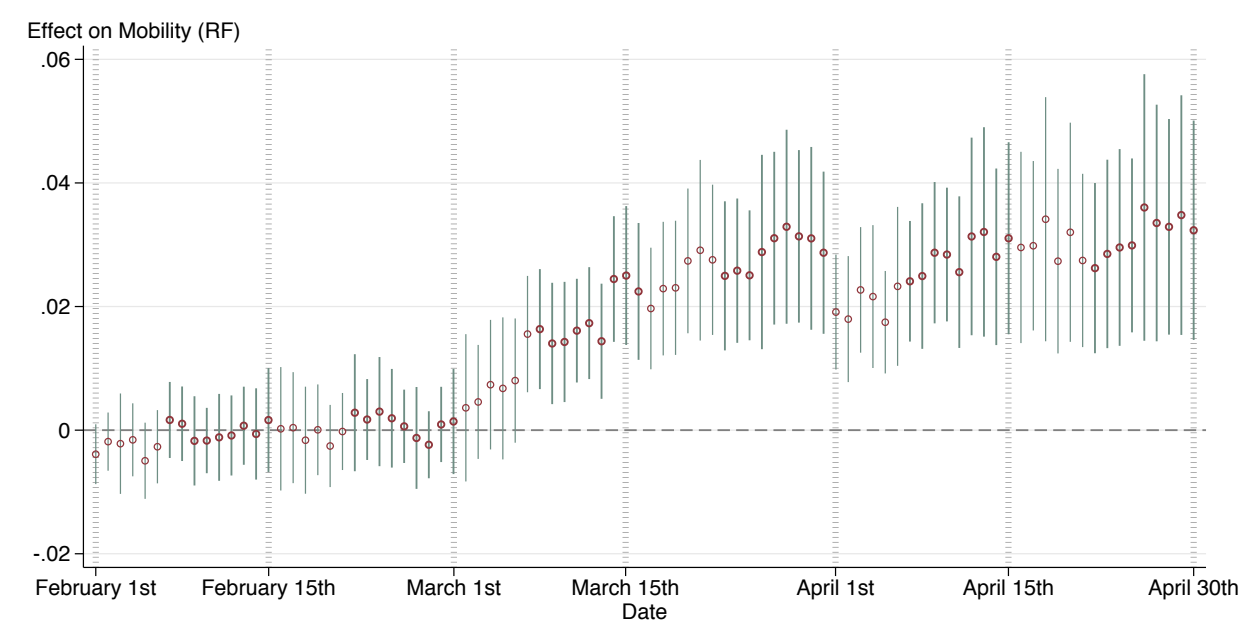

(b) Time outside home - FXNC

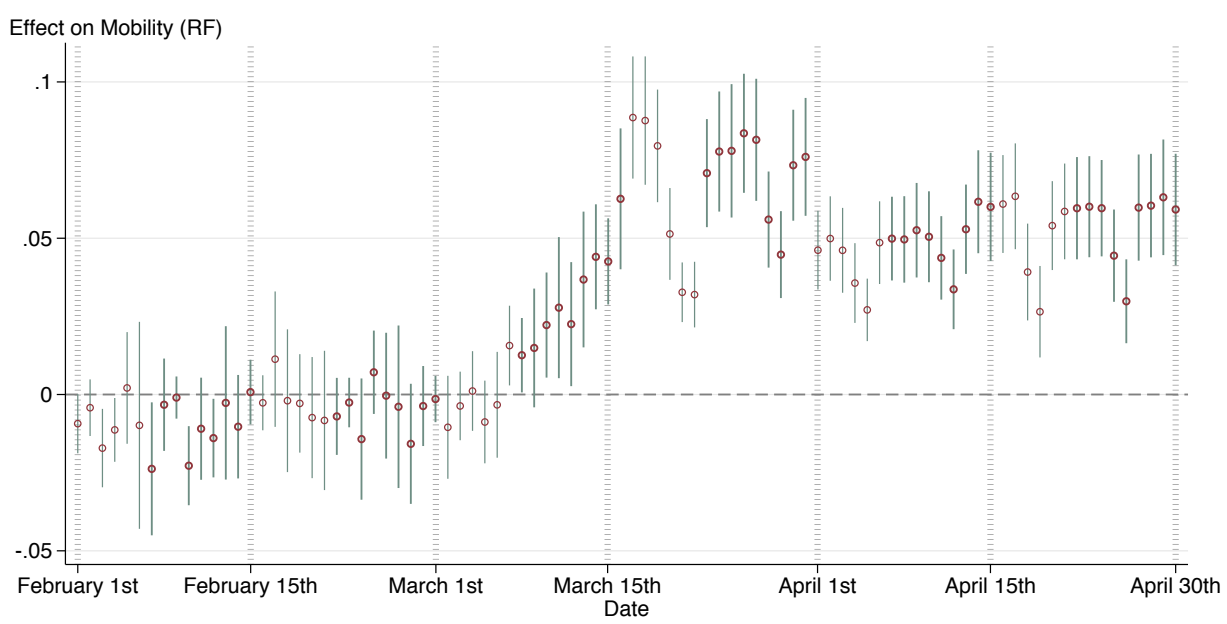

Notes: Reduced Form (RF) regression results (Equation 3) for the effect of FNC on mobility outcomes, analogous to 2SLS results in Figure 3. 
Figure A.3: Effect on Mobility Outcomes: Reduced Form, Zip-code level with County FE

(a) Distance from home

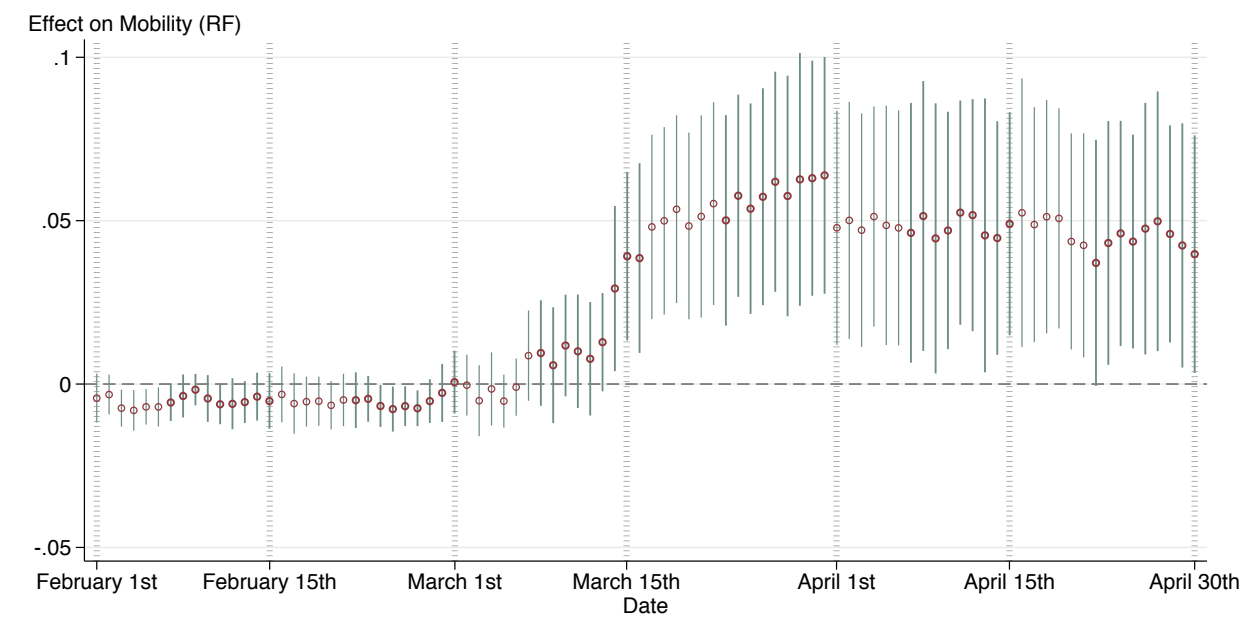

(b) Time outside home

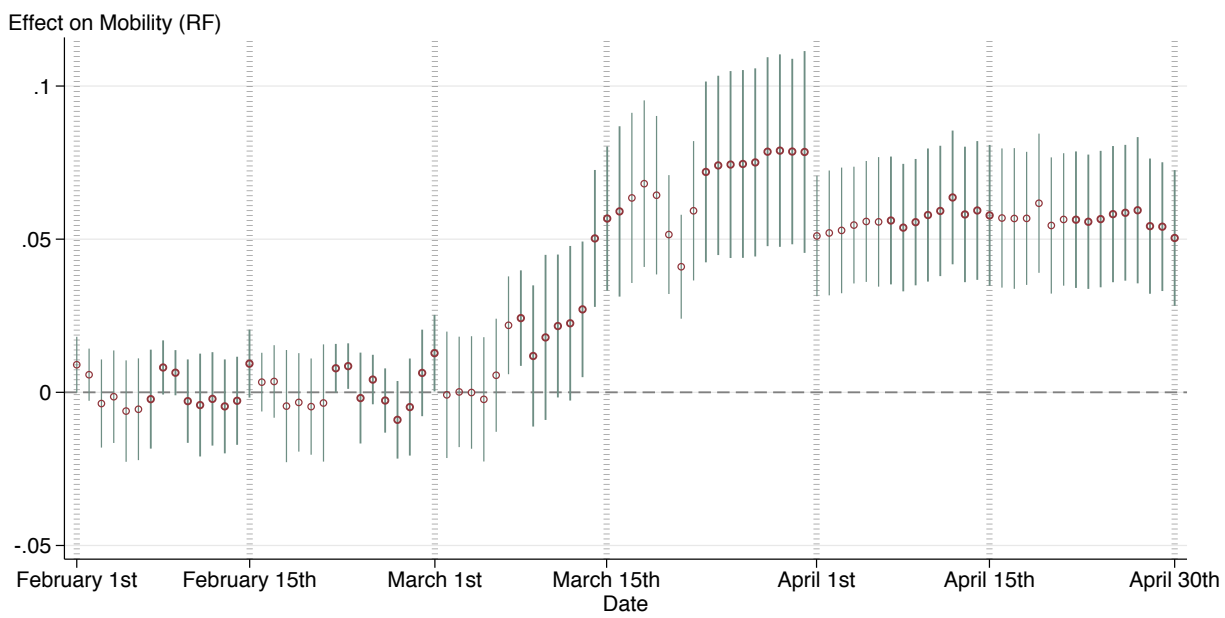

Notes: Reduced Form (RF) regression results (Equation 3) for the effect of FNC on mobility outcomes, zipcode-level (rather than county-level) specification. The important difference is the inclusion of County fixed effects, rather than state fixed effects. County-level covariates are dropped (Republican vote share, ratings controls for CNN and MSNBC). Standard errors still clustered by state.. 
Figure A.4: Effect on Mobility Outcomes: Robustness to Polynomials and Interactions of unbalanced covariates

(a) Distance from home

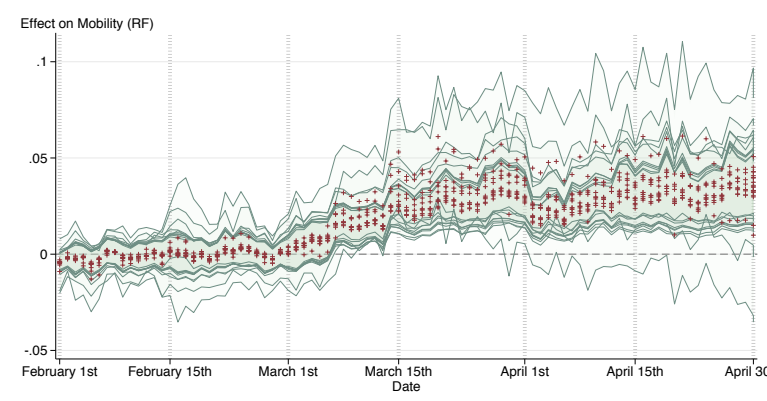

(b) Time outside home

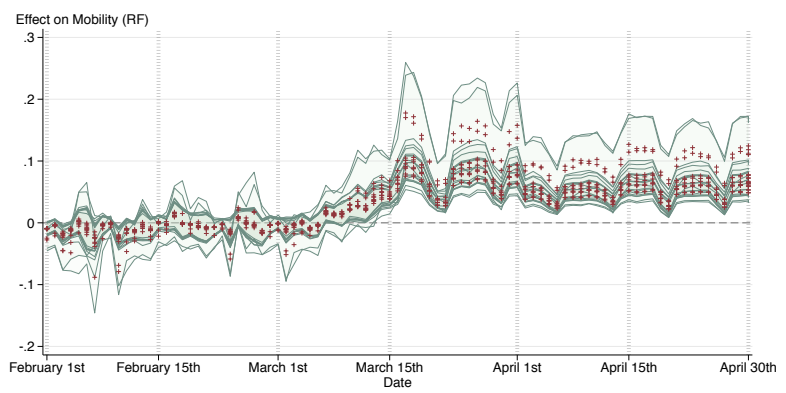

(c) Covid Purchases

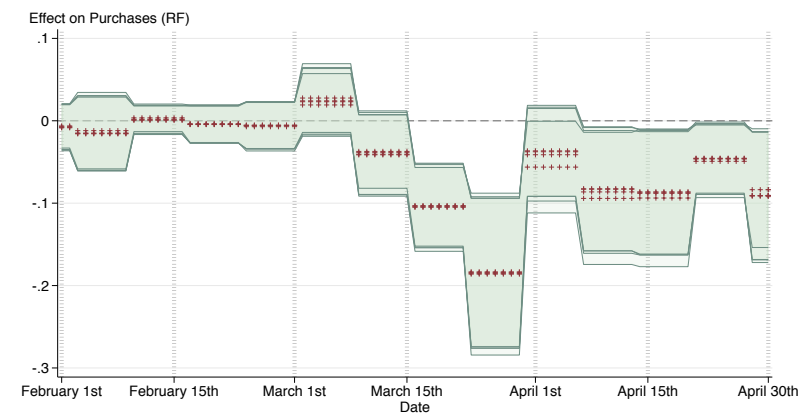

Notes: Reduced Form (RF) regression results (Equation 3) for the effect of FNC on mobility outcomes - Panel (a) \& (b) and purchases - Panel (c).

Panels (a)-(b) show 10 sets of regressions on our two main mobility outcomes. The specification includes our standard set of controls for the County level (socio-demographic and CNN and MSNBC viewership), weighted observations, with State FE's and State clustered standard errors and January day-of-the-week baseline controls. The specifications further include, for one of the five controls significant at the $10 \%$ in the instrument check at the County and Zipcode level on the main sample, either an interaction with the instrument or a polynomial regression: Population density, Area, Food stamps, White pop ab. median (county level sample) and No high school, Area (zipcode level sample). Of these controls only area is significant at the $5 \%$. The interaction regressions and the polynomial regressions for all the problematic controls are overlapped by outcome. Results appear robust.

Panel (c) shows 4 sets of regressions on the purchases outcome. The specification uses the purchases restricted sample of zipcodes, with weighted observations, State FE's and State clustered standard errors. The specifications further include, for one of the four controls significant at the $10 \%$ in the instrument check further includes for one of the problematic controls of the instrument check a polynomial regression: Area, Age imbalance, No high school, Male. The polynomial regressions for all the problematic controls are overlapped. Results are robust to the polynomials even without the inclusion of the baseline measure. 
Figure A.5: Effect on Mobility, Robustness to dropping individual controls

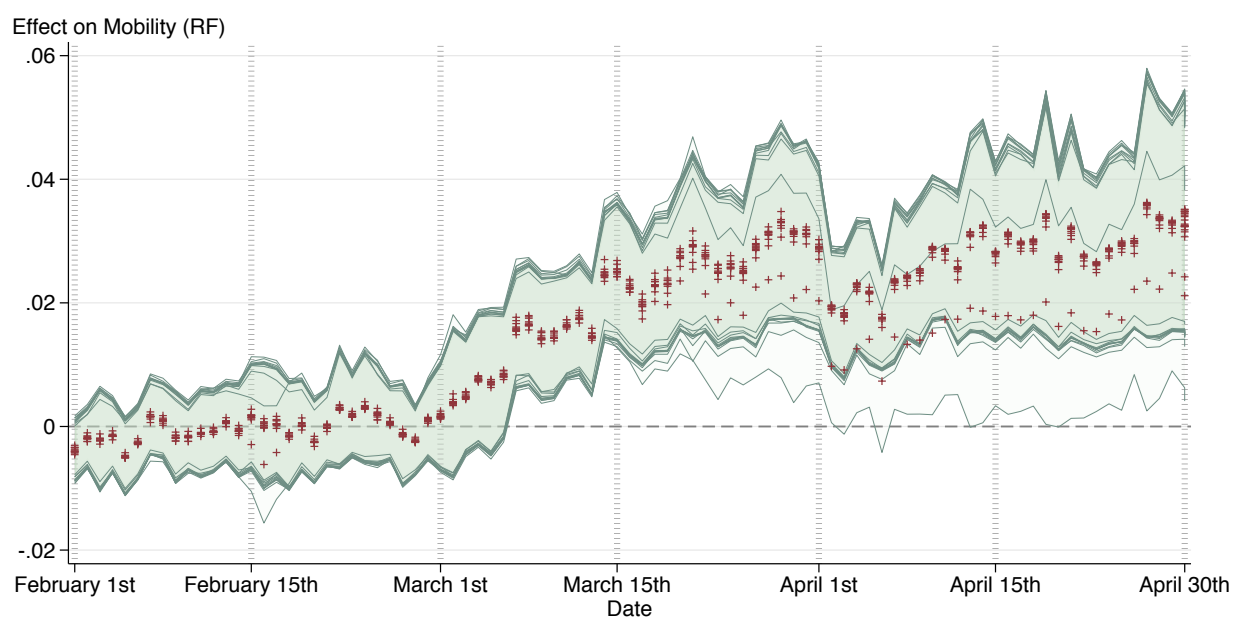

Notes: We run here our main specification Reduced Form regressions at the county level, dropping every time one of the census controls: population density, land area of the county, age imbalance in the population, percentage of people having access to food stamps, above median republican share of the county in 2012 US Elections above median, above median republican share of the county in 2016 US Elections above median, percentage of population with no high school education, percentage of population with college education, above median percentage of white people, above median percentage of black people, percentage of males. We plot therefore 11 different sets of regressions. Confidence intervals are at the $95 \%$. The set of regressions lower in the graph are the ones when dropping population density, a key control in the analysis. The 2SLS regressions are also robust to the robustness check. 
Figure A.6: Effect on Mobility, Robustness to dropping individual states

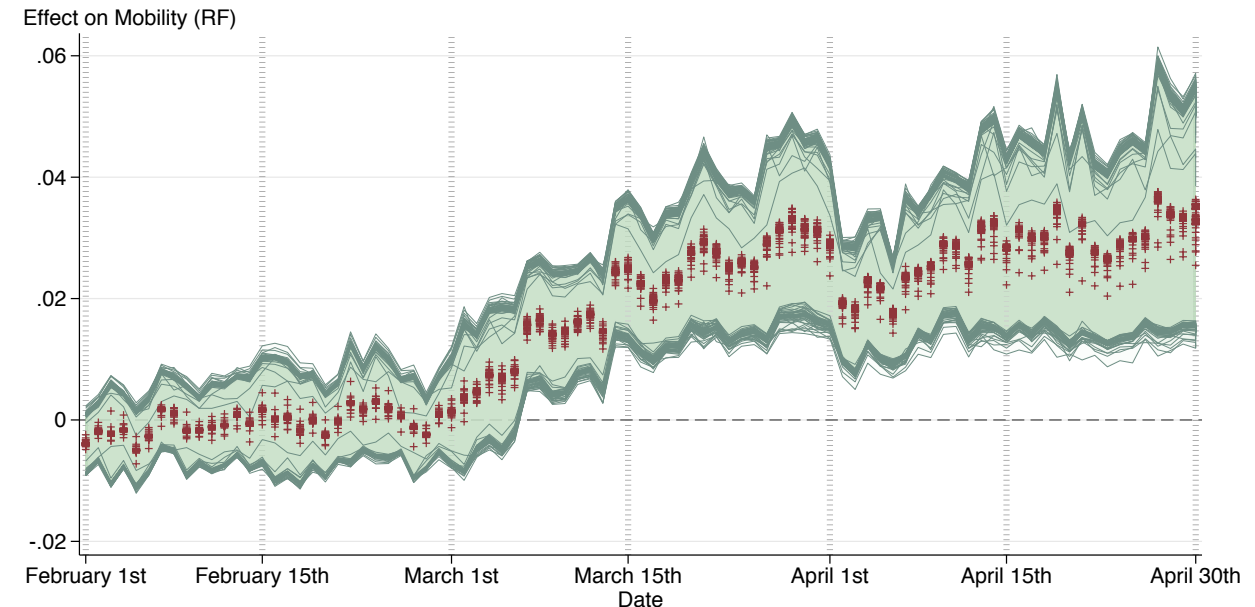

Notes: We run here our main specification Reduced Form regressions at the county level, dropping one of the 49 states at the time. We plot therefore 49 different sets of regressions. Confidence intervals are at the $95 \%$. The 2SLS regressions are also robust to the robustness check, however, the first stage regressions lose significance with the reduced sample size. 
Figure A.7: Effect on Mobility, Robustness to dropping January baseline

(a) Distance from home

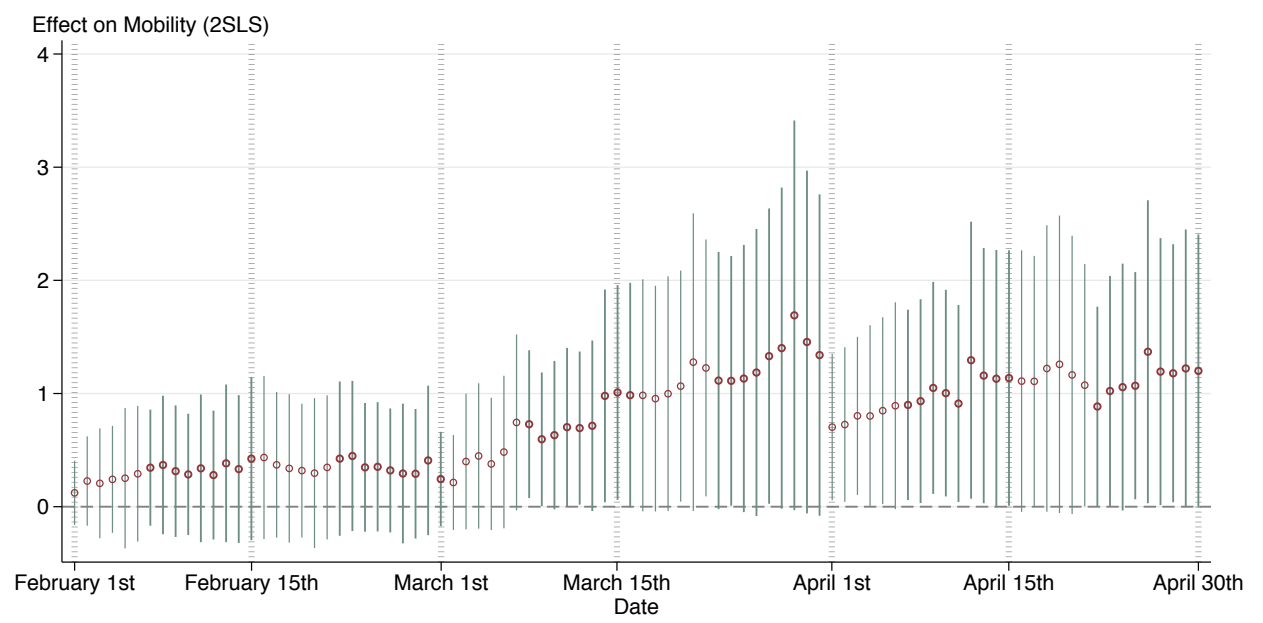

(b) Time outside home

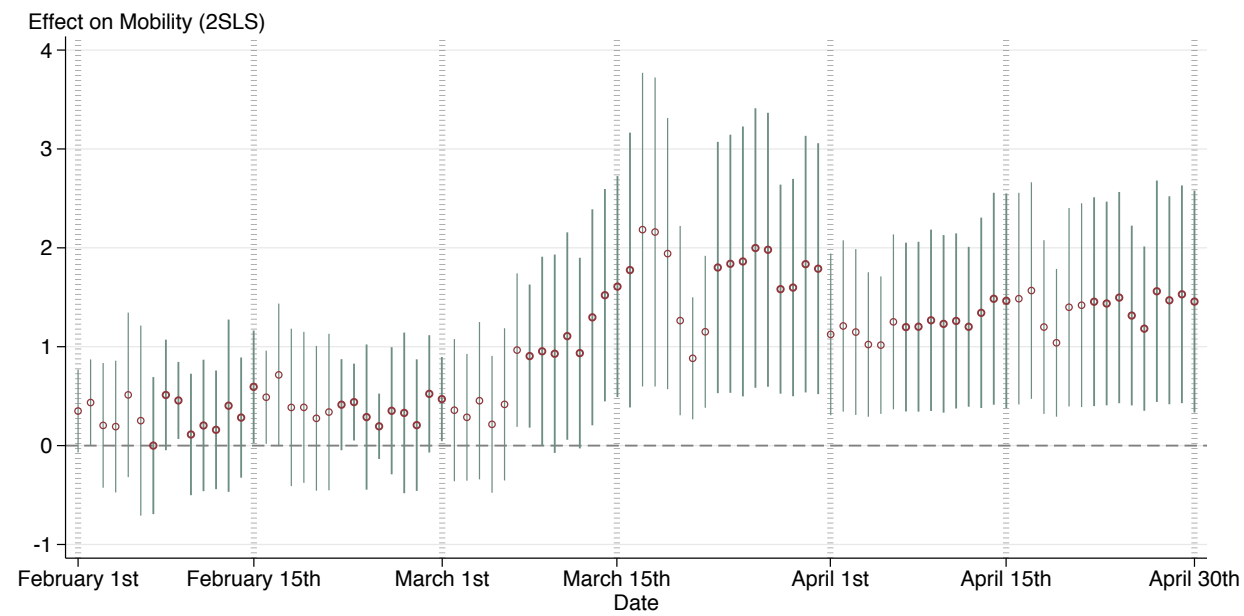

Notes: 2SLS regression results for our main FNC specification for mobility outcomes in Figure 3, not controlling for the January day-of-the-week baseline. Results are robust to the omission of the baseline. 
Figure A.8: Effect on Additional Mobility Outcomes

(a) Part time workers

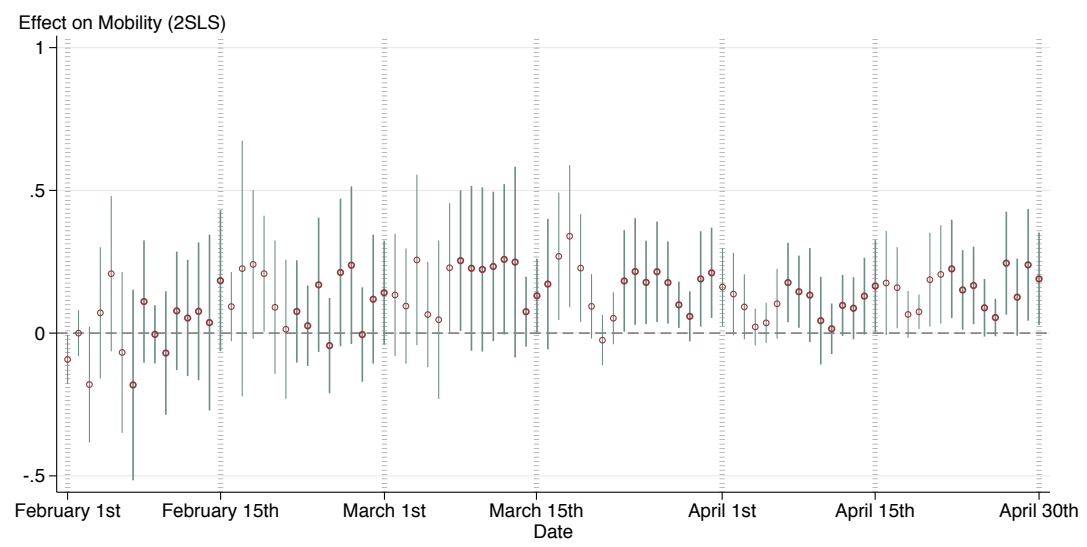

(b) Full time workers

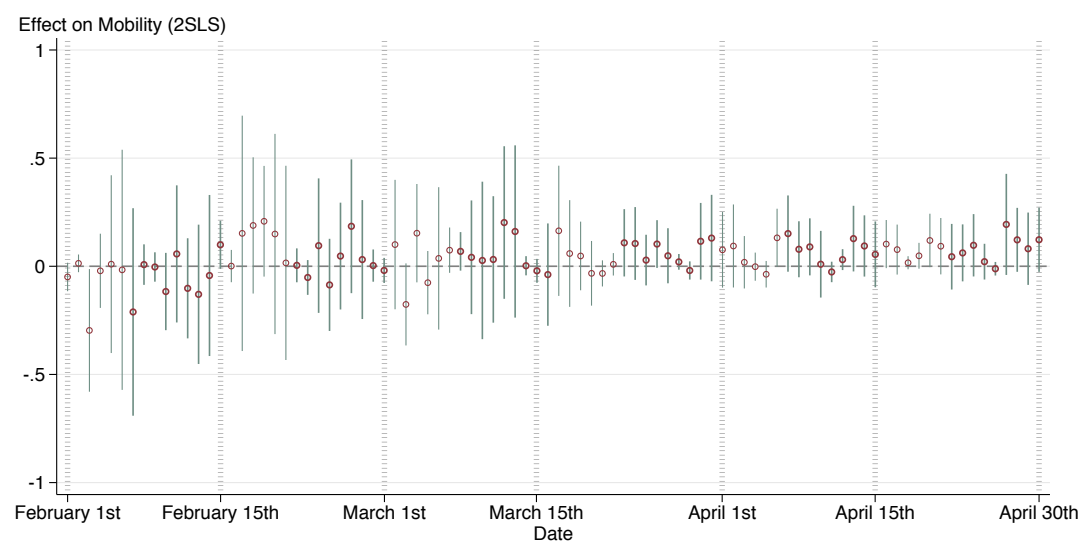

(c) Home devices count

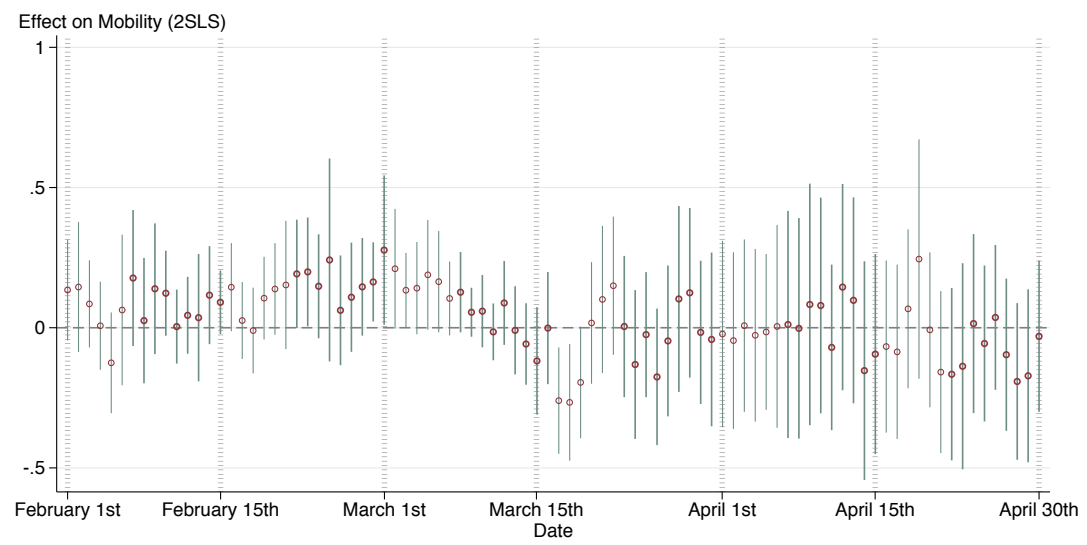

Notes: We include here two further outcomes for mobility, the number of devices of part time workers (defined as devices being outside home during day for 3 to 6 hours) and the number of devices completely at home. The specification follows the main mobility regressions with weighted observations, State FE's and State clustered standard errors, census controls, political elections controls and CNN and MSNBC ratings, and including the January day-of-the-week baseline. We find a significant effect on part-time workers but not on the number of devices at home. 
Figure A.9: Effect on Purchases, Limited to Protective Products

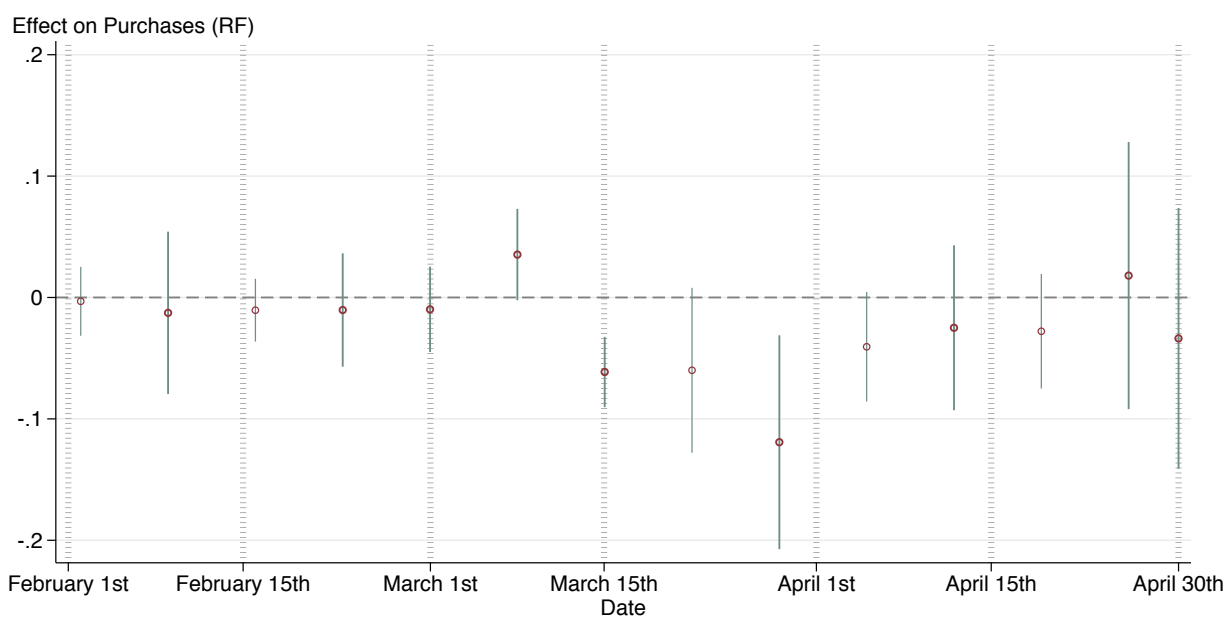

Notes: We look here at the total expenditure in a subset of products: cleaning products, facial masks and hand sanitiser. The specification uses the purchases restricted sample, with weighted observations, State fe's and State clustered standard errors. The specifications further include, for one of the four controls significant at the $10 \%$ in the instrument check further includes for one of the problematic controls of the instrument check a polynomial regression: Area, Age imbalance, No high school, Male. The polynomial regressions for all the problematic controls are overlapped. Results are robust to the polynomials even without the inclusion of the baseline measure. 
Figure A.10: Placebo Test: Effect on 2019 Mobility (2SLS)

(a) Distance from home

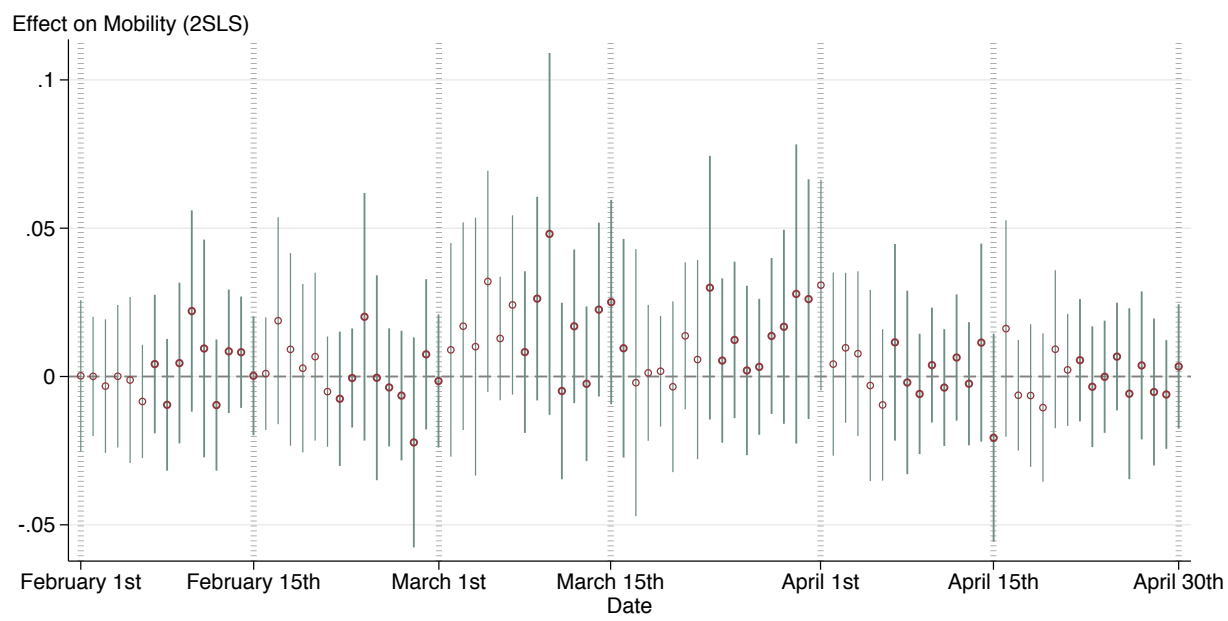

(b) Time outside home

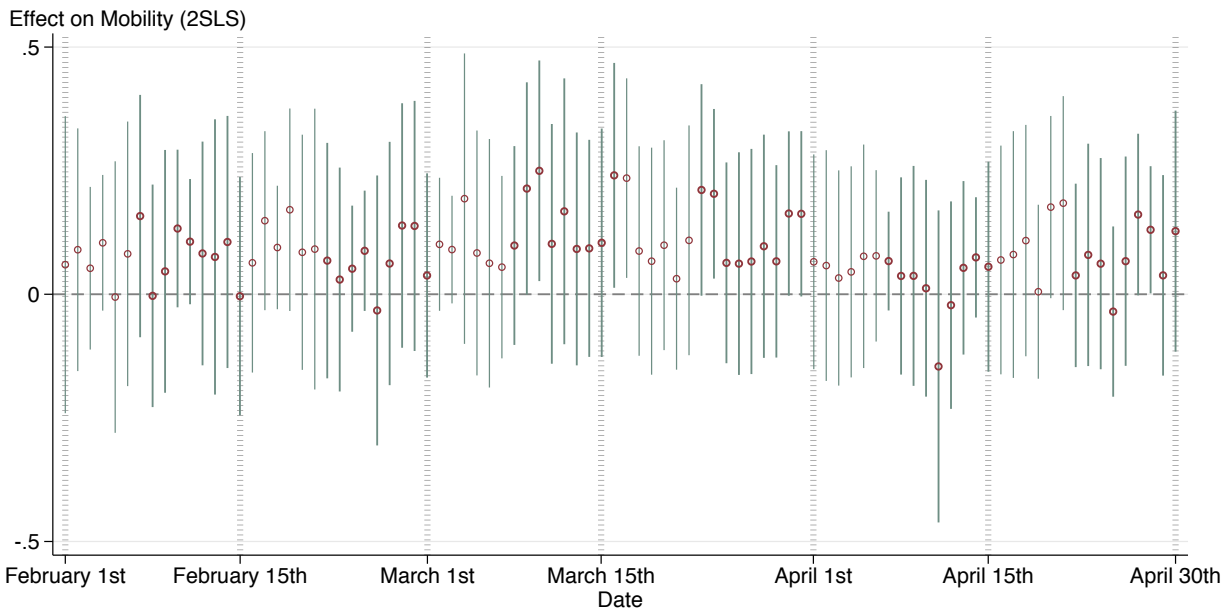

Notes: We run here our main specification 2SLS regressions at the county level as in Figure 3 but on the 2019 mobility data, without January day-of-the-week baseline. Confidence intervals are at the $95 \%$. 
Figure A.11: Effect on Mobility of CNN/MSNBC (OLS)

(a) Distance from home - MSNBC

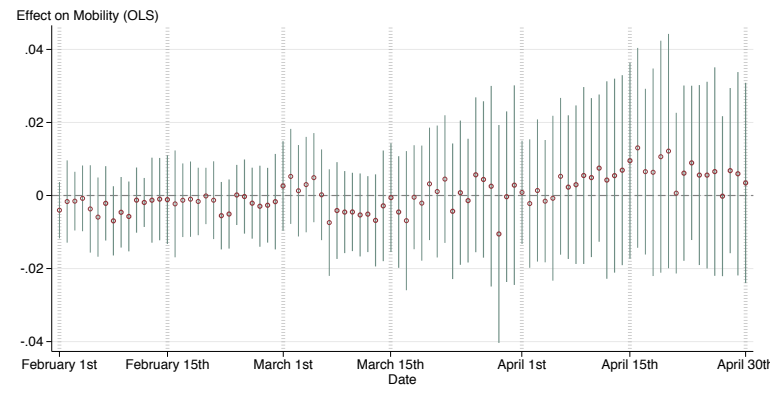

(c) Distance from home - CNN

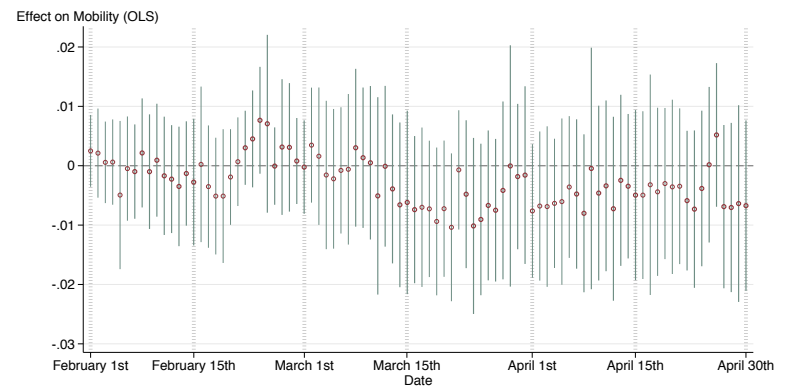

(b) Time outside home - MSNBC

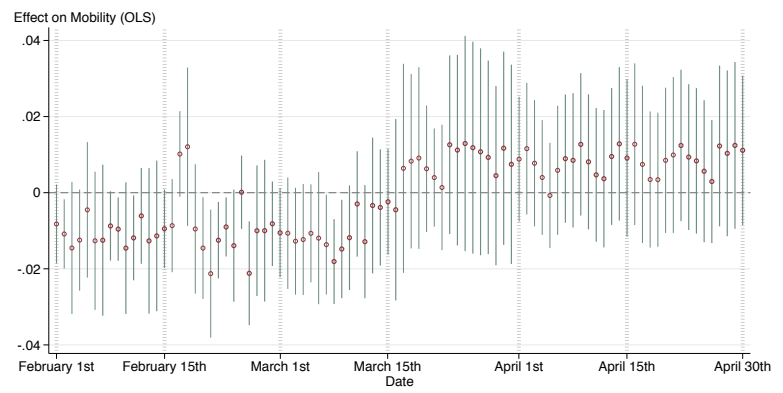

(d) Time outside home - CNN

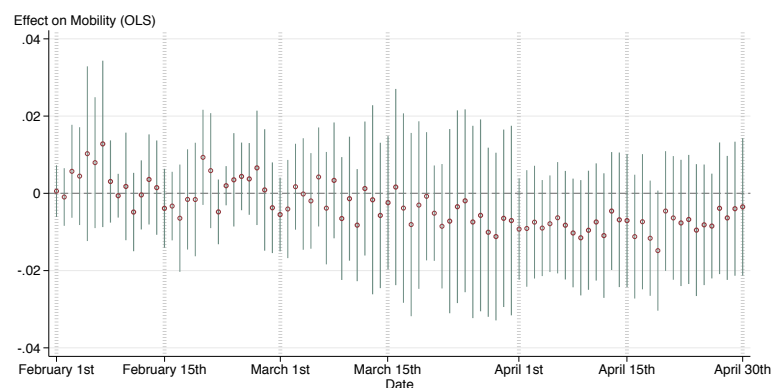

Notes: The OLS specification for CNN and MSNBC follows the same specification as the main Fox News Channel specification for the mobility sample: weighted observations, with State FE's and State clustered standard errors and January day-of-the-week baseline controls. The viewership controls included in the specification are those of the other two main networks: FXNC and CNN for MSNBC and FXNC and MSNBC for CNN.. 
Figure A.12: Effect on Mobility of CNN/MSNBC (2SLS)

(a) Distance from home - MSNBC

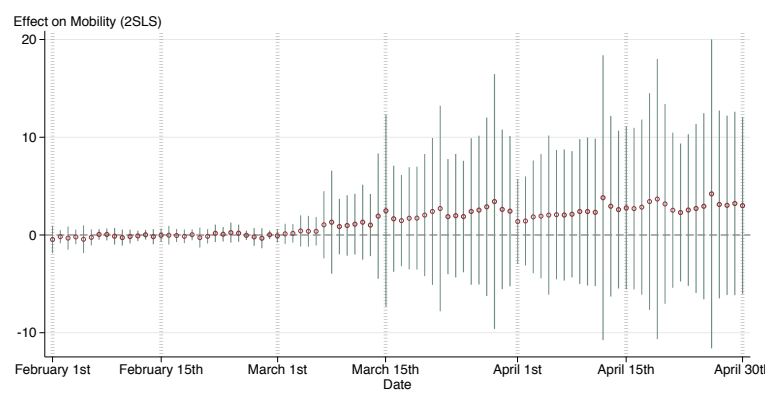

(c) Distance from home - CNN

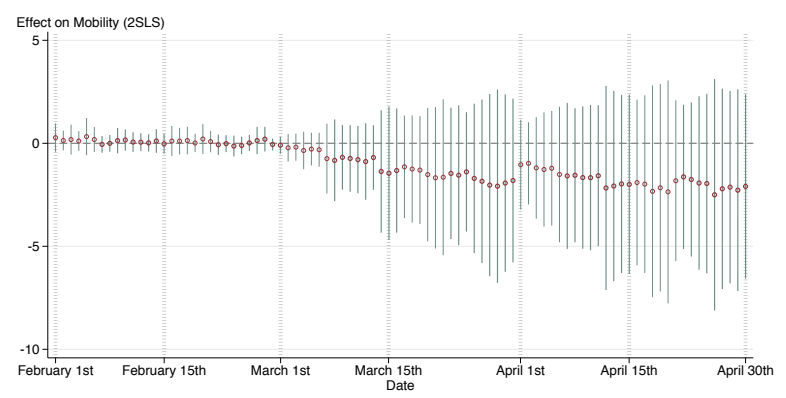

(b) Time outside home - MSNBC

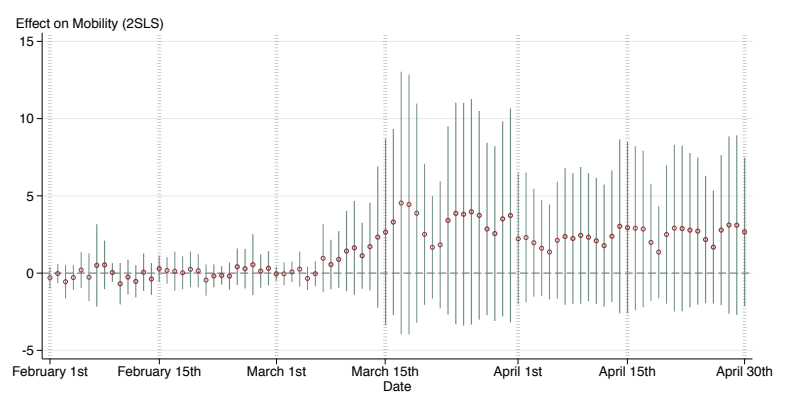

(d) Time outside home - CNN

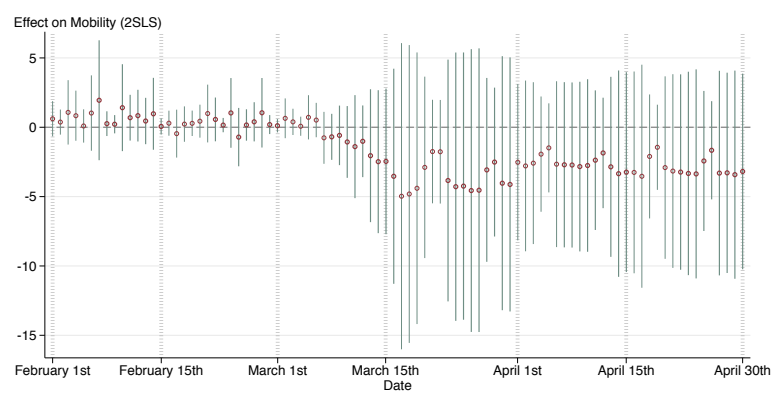

Notes: The 2SLS specification for CNN and MSNBC follows the same specification as the main Fox News Channel specification for the mobility sample: weighted observations, with State FE's and State clustered standard errors and January day-of-the-week baseline controls. The viewership controls included in the specification are those of the other two main networks: FXNC and CNN for MSNBC and FXNC and MSNBC for CNN.. 
Table A.3: 2SLS Estimates - Distance from home

\begin{tabular}{|c|c|c|c|c|c|c|c|c|}
\hline Date & Coefficient & st. errors & Date & Coefficient & st. errors & Date & Coefficient & st. errors \\
\hline 01-Feb-20 & -0.0947 & $(0.0621)$ & 02-Mar-20 & 0.0865 & $(0.147)$ & 01-Apr-20 & 0.459* & $(0.192)$ \\
\hline 02-Feb-20 & .0454 & $(0.0576)$ & 03-Mar-20 & 0.109 & $(0.117)$ & 02-Apr-20 & $0.430 *$ & $(0.188)$ \\
\hline 03-Feb-20 & -0.0524 & $(0.0965)$ & 4-Mar-20 & 0.177 & $(0.143)$ & $03-A p r-20$ & $0.549^{*}$ & $(0.216)$ \\
\hline 04-Feb-20 & -0.0375 & $(0.0701)$ & 05-Mar-20 & 0.162 & $(0.151)$ & 04-Apr-20 & $0.526^{*}$ & $(0.250)$ \\
\hline 05-Feb-20 & -0.119 & $(0.0788)$ & 06-Mar-20 & 0.194 & $(0.137)$ & 05-Apr-20 & $0.428^{*}$ & $(0.194)$ \\
\hline 06-Feb-20 & -0.0642 & $(0.0733)$ & 07-Mar-20 & $0.378^{*}$ & $(0.171)$ & 06-Apr-20 & $0.557^{*}$ & $(0.256)$ \\
\hline 07-Feb-20 & 0.0399 & $(0.0751)$ & 08-Mar-20 & $0.400^{*}$ & $(0.175)$ & 07-Apr-20 & $0.577^{*}$ & $(0.236)$ \\
\hline 08-Feb-20 & 0.0252 & $(0.0732)$ & 09-Mar-20 & $0.336^{*}$ & $(0.158)$ & $08-A p r-20$ & $0.599^{*}$ & $(0.258)$ \\
\hline 09-Feb-20 & -0.0424 & $(0.0882)$ & 10-Mar-20 & $0.342^{*}$ & $(0.159)$ & 09-Apr-20 & $0.687^{*}$ & $(0.260)$ \\
\hline 10-Feb-20 & -0.0402 & $(0.0639)$ & 11-Mar-20 & $0.387^{*}$ & $(0.160)$ & 10-Apr-20 & $0.688^{*}$ & $(0.268)$ \\
\hline 11-Feb-20 & -0.0279 & $(0.0841)$ & 12-Mar-20 & $0.415^{*}$ & $(0.174)$ & 11-Apr-20 & $0.622^{*}$ & $(0.275)$ \\
\hline $12-F e b-20$ & -0.0207 & $(0.0772)$ & 13-Mar-20 & $0.348^{*}$ & $(0.155)$ & $12-A p r-20$ & $0.767^{*}$ & $(0.338)$ \\
\hline 13-Feb-20 & 0.0171 & $(0.0757)$ & 14-Mar-20 & $0.595^{*}$ & $(0.243)$ & 13-Apr-20 & $0.767^{*}$ & $(0.340)$ \\
\hline $14-F e b-20$ & -0.0149 & $(0.0887)$ & 15 -Mar-20 & $0.613^{*}$ & $(0.273)$ & $14-A p r-20$ & $0.672^{*}$ & $(0.305)$ \\
\hline 15-Feb-20 & 0.0398 & $(0.104)$ & 16-Mar-20 & $0.537^{*}$ & $(0.242)$ & 15 -Apr-20 & $0.745^{*}$ & $(0.332)$ \\
\hline $16-F e b-20$ & 0.00540 & $(0.122)$ & 17-Mar-20 & $0.472^{*}$ & $(0.215)$ & $16-A p r-20$ & $0.708^{*}$ & $(0.317)$ \\
\hline 17-Feb-20 & 0.00964 & $(0.107)$ & 18-Mar-20 & $0.550^{*}$ & $(0.250)$ & 17-Apr-20 & $0.722^{*}$ & $(0.309)$ \\
\hline 18-Feb-20 & -0.0390 & $(0.103)$ & 19-Mar-20 & $0.551^{*}$ & $(0.250)$ & 18-Apr-20 & $0.830^{*}$ & $(0.397)$ \\
\hline 19-Feb-20 & 0.00141 & $(0.0877)$ & 20-Mar-20 & $0.663^{*}$ & $(0.278)$ & $19-A p r-20$ & $0.669^{*}$ & $(0.313)$ \\
\hline 20-Feb-20 & -0.0614 & $(0.0803)$ & 21-Mar-20 & $0.708^{*}$ & $(0.321)$ & 20-Apr-20 & $0.766^{*}$ & $(0.365)$ \\
\hline 21-Feb-20 & -0.00526 & $(0.0751)$ & 22-Mar-20 & $0.675^{*}$ & $(0.282)$ & $21-A p r-20$ & $0.658^{*}$ & $(0.297)$ \\
\hline $22-F e b-20$ & 0.0687 & $(0.118)$ & 23-Mar-20 & $0.597^{*}$ & $(0.255)$ & 22 -Apr-20 & $0.629^{*}$ & $(0.290)$ \\
\hline $23-F e b-20$ & 0.0422 & $(0.0805)$ & 24-Mar-20 & $0.618^{*}$ & $(0.269)$ & $23-A p r-20$ & $0.683^{*}$ & $(0.314)$ \\
\hline 24-Feb-20 & 0.0718 & $(0.108)$ & 25-Mar-20 & $0.601 *$ & $(0.254)$ & 24-Apr-20 & $0.716^{*}$ & $(0.337)$ \\
\hline $25-F e b-20$ & 0.0461 & $(0.0973)$ & 26-Mar-20 & $0.690^{*}$ & $(0.328)$ & $25-A p r-20$ & $0.727^{*}$ & $(0.307)$ \\
\hline 26-Feb-20 & 0.0149 & $(0.0713)$ & 27-Mar-20 & $0.752^{*}$ & $(0.316)$ & 26-Apr-20 & $0.882^{*}$ & $(0.417)$ \\
\hline 27-Feb-20 & -0.0302 & $(0.0978)$ & 28-Mar-20 & $0.801^{*}$ & $(0.344)$ & 27-Apr-20 & $0.802^{*}$ & $(0.369)$ \\
\hline 28-Feb-20 & -0.0572 & $(0.0666)$ & 29-Mar-20 & $0.768^{*}$ & $(0.317)$ & 28-Apr-20 & $0.788^{*}$ & $(0.348)$ \\
\hline 29-Feb-20 & 0.0225 & $(0.0760)$ & 30-Mar-20 & $0.742^{*}$ & $(0.319)$ & 29-Apr-20 & $0.835^{*}$ & $(0.377)$ \\
\hline 01-Mar-20 & 0.0344 & $(0.107)$ & 31-Mar-20 & $0.688^{*}$ & $(0.299)$ & 30-Apr-20 & $0.774^{*}$ & $(0.356)$ \\
\hline
\end{tabular}

Notes: Standard errors clustered by state. ${ }^{*} \mathrm{p}<0.05$ and ${ }^{* *} \mathrm{p}<0.01$. 
Table A.4: 2SLS Estimates - Time outside home

\begin{tabular}{|c|c|c|c|c|c|c|c|c|}
\hline Date & Coefficient & st. errors & Date & Coefficient & st. errors & Date & Coefficient & st. errors \\
\hline 01-Feb-20 & $-0.208^{*}$ & $(0.101)$ & 02-Mar-20 & -0.232 & $(0.183)$ & 01-Apr-20 & $1.023^{* *}$ & $(0.342)$ \\
\hline 02-Feb-20 & -0.0985 & $(0.105)$ & 03-Mar-20 & -0.0805 & $(0.114)$ & 02-Apr-20 & $1.101^{* *}$ & $(0.362)$ \\
\hline 03-Feb-20 & $-0.379^{*}$ & $(0.156)$ & 04-Mar-20 & 0.0248 & $(0.142)$ & 03-Apr-20 & $1.021^{* *}$ & $(0.348)$ \\
\hline 04-Feb-20 & $-0.250^{*}$ & $(0.119)$ & 05-Mar-20 & -0.194 & $(0.141)$ & 04-Apr-20 & $0.799^{*}$ & $(0.305)$ \\
\hline 05-Feb-20 & 0.0466 & $(0.196)$ & 06-Mar-20 & -0.0729 & $(0.180)$ & 05-Apr-20 & $0.633^{*}$ & $(0.239)$ \\
\hline 06-Feb-20 & -0.218 & $(0.380)$ & 07-Mar-20 & 0.351 & $(0.206)$ & 06-Apr-20 & $1.073^{* *}$ & $(0.353)$ \\
\hline 07-Feb-20 & $-0.526^{*}$ & $(0.248)$ & 08-Mar-20 & 0.294 & $(0.182)$ & 07-Apr-20 & $1.099^{* *}$ & $(0.361)$ \\
\hline 08-Feb-20 & -0.0731 & $(0.160)$ & 09-Mar-20 & 0.329 & $(0.233)$ & 08-Apr-20 & $1.099^{* *}$ & $(0.363)$ \\
\hline 09-Feb-20 & -0.0228 & $(0.0773)$ & 10-Mar-20 & 0.490 & $(0.246)$ & 09-Apr-20 & $1.160^{* *}$ & $(0.386)$ \\
\hline 10-Feb-20 & $-0.503^{* *}$ & $(0.184)$ & 11-Mar-20 & $0.615^{*}$ & $(0.292)$ & 10-Apr-20 & $1.116^{* *}$ & $(0.383)$ \\
\hline $11-F e b-20$ & -0.241 & $(0.184)$ & 12-Mar-20 & 0.497 & $(0.252)$ & 11-Apr-20 & $0.979^{* *}$ & $(0.363)$ \\
\hline 12-Feb-20 & -0.309 & $(0.172)$ & 13-Mar-20 & $0.814^{*}$ & $(0.332)$ & 12-Apr-20 & $0.787^{*}$ & $(0.294)$ \\
\hline 13-Feb-20 & -0.0591 & $(0.270)$ & 14-Mar-20 & $0.986^{*}$ & $(0.387)$ & 13-Apr-20 & $1.168^{* *}$ & $(0.392)$ \\
\hline 14-Feb-20 & -0.228 & $(0.197)$ & 15-Mar-20 & $0.995^{*}$ & $(0.378)$ & 14-Apr-20 & $1.359^{* *}$ & $(0.452)$ \\
\hline 15 -Feb-20 & 0.0176 & $(0.118)$ & 16-Mar-20 & $1.383^{* *}$ & $(0.488)$ & 15-Apr-20 & $1.329^{* *}$ & $(0.455)$ \\
\hline 16-Feb-20 & -0.0619 & $(0.0994)$ & 17-Mar-20 & $1.953^{* *}$ & $(0.637)$ & 16-Apr-20 & $1.345^{* *}$ & $(0.445)$ \\
\hline 17-Feb-20 & 0.250 & $(0.234)$ & 18-Mar-20 & $1.941^{* *}$ & (0.639) & 17-Apr-20 & $1.403^{* *}$ & $(0.459)$ \\
\hline 18-Feb-20 & -0.0438 & $(0.251)$ & 19-Mar-20 & $1.756^{* *}$ & $(0.564)$ & 18-Apr-20 & $0.877^{*}$ & $(0.349)$ \\
\hline $19-F e b-20$ & -0.0629 & $(0.174)$ & 20-Mar-20 & $1.136^{* *}$ & $(0.406)$ & 19-Apr-20 & $0.619^{*}$ & $(0.268)$ \\
\hline $20-F e b-20$ & -0.163 & $(0.214)$ & 21-Mar-20 & $0.733^{* *}$ & $(0.266)$ & 20-Apr-20 & $1.193^{* *}$ & $(0.396)$ \\
\hline 21-Feb-20 & -0.184 & $(0.240)$ & 22-Mar-20 & $0.747^{* *}$ & $(0.274)$ & 21-Apr-20 & $1.291^{* *}$ & $(0.431)$ \\
\hline 22-Feb-20 & -0.157 & $(0.126)$ & 23-Mar-20 & $1.564^{* *}$ & $(0.518)$ & 22-Apr-20 & $1.320^{* *}$ & $(0.438)$ \\
\hline 23-Feb-20 & -0.0599 & $(0.0918)$ & 24-Mar-20 & $1.713^{* *}$ & $(0.567)$ & 23-Apr-20 & $1.326^{* *}$ & $(0.441)$ \\
\hline $24-F e b-20$ & -0.315 & $(0.227)$ & 25-Mar-20 & $1.726^{* *}$ & $(0.590)$ & 24-Apr-20 & $1.319^{* *}$ & $(0.438)$ \\
\hline 25-Feb-20 & 0.157 & $(0.156)$ & 26-Mar-20 & $1.845^{* *}$ & $(0.602)$ & 25-Apr-20 & $0.995^{* *}$ & $(0.365)$ \\
\hline 26-Feb-20 & -0.00813 & $(0.222)$ & 27-Mar-20 & $1.803^{* *}$ & $(0.592)$ & 26-Apr-20 & $0.697^{*}$ & $(0.285)$ \\
\hline 27-Feb-20 & -0.0865 & $(0.286)$ & 28-Mar-20 & $1.253^{* *}$ & $(0.435)$ & 27-Apr-20 & $1.321^{* *}$ & $(0.438)$ \\
\hline 28 -Feb-20 & -0.349 & $(0.220)$ & 29-Mar-20 & $1.046^{* *}$ & $(0.390)$ & 28-Apr-20 & $1.332^{\text {** }}$ & $(0.437)$ \\
\hline 29-Feb-20 & -0.0825 & $(0.133)$ & 30-Mar-20 & $1.620^{* *}$ & $(0.533)$ & 29-Apr-20 & $1.397^{* *}$ & $(0.465)$ \\
\hline 01-Mar-20 & -0.0336 & $(0.0846)$ & 31-Mar-20 & $1.676^{* *}$ & $(0.553)$ & 30-Apr-20 & $1.306^{* *}$ & $(0.462)$ \\
\hline
\end{tabular}

Notes: Standard errors clustered by state. ${ }^{*} \mathrm{p}<0.05$ and ${ }^{* *} \mathrm{p}<0.01$. 
Table A.5: Reduced Form Estimates - Covid-Related Purchases

\begin{tabular}{lcc}
\hline Date & Coefficient & st. errors \\
\hline 27-Jan/2-Feb-20 & -0.00802 & $(0.0123)$ \\
3/9-Feb-20 & -0.0156 & $(0.0197)$ \\
10/16-Feb-20 & 0.00154 & $(0.00768)$ \\
17/23-Feb-20 & -0.00420 & $(0.0101)$ \\
24-Feb/1-Mar-20 & -0.00509 & $(0.0126)$ \\
2/8-Mar-20 & 0.0257 & $(0.0187)$ \\
9/14-Mar-20 & -0.0402 & $(0.0222)$ \\
15/21-Mar-20 & $-0.104^{* *}$ & $(0.0223)$ \\
22/28-Mar-20 & $-0.184^{* *}$ & $(0.0399)$ \\
29-Mar/5-Apr-20 & -0.0388 & $(0.0244)$ \\
6/12-Apr-20 & $-0.0836^{*}$ & $(0.0331)$ \\
13/19-Apr-20 & $-0.0857^{*}$ & $(0.0332)$ \\
20/26-Apr-20 & $-0.0457^{*}$ & $(0.0189)$ \\
27-Apr/3-May-20 & $-0.0904^{*}$ & $(0.0345)$ \\
\hline
\end{tabular}

Notes: Standard errors clustered by state. ${ }^{*} \mathrm{p}<$ 0.05 and ${ }^{* *} \mathrm{p}<0.01$. 


\section{A6. Additional Health Results}

This section reports additional results on the public-health outcomes. We note that the pandemic situation is still evolving. It could be that media messaging will influence behaviors and health in subsequent stages. Both the imposition and the disengagement of lockdowns has been politicized, with divisive messaging on both sides. We will continue to monitor these subsequent events and potential impacts. 
Figure A.13: Fox News Effect on COVID-19 Outcomes

(a)

Number of cases (per capita)

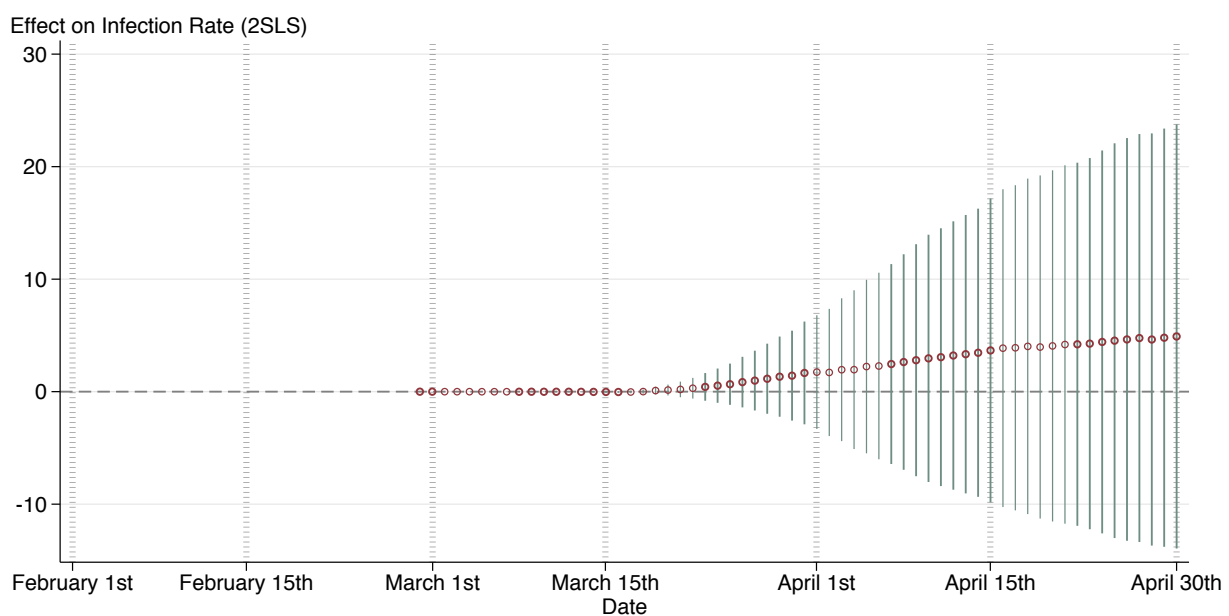

(b)

Number of deaths (per capita)

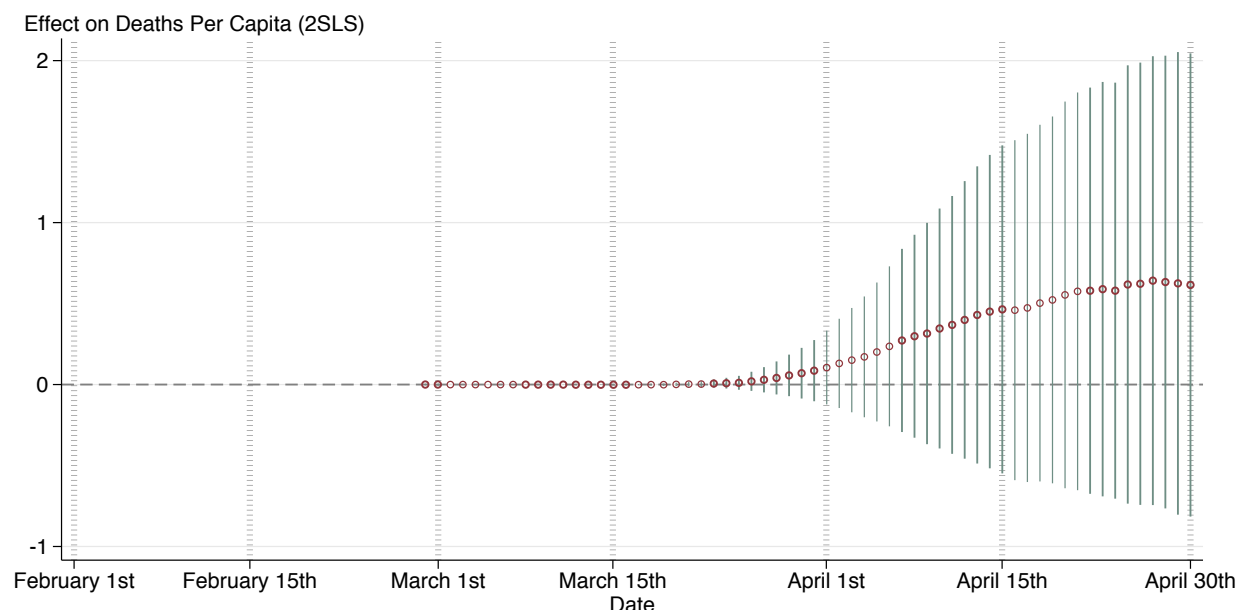

Notes: Each panel in this figure shows a series of coefficient plots and 95\% confidence intervals for daily regressions of the effect of Fox News Channel viewership on cases and deaths per capita measures. Specification is the same is in the main COVID-19 regressions, with weighted observations, State FE's and State clustered standard errors, census controls, political elections controls and CNN and MSNBC ratings. The per capita measure is defined as cumulative cases/deaths over population times 1000. Some extremely sparse cases and deaths are reported in February and generate very noisy estimates, making the graph unreadable, we exclude those therefore for presentation purposes. 
Figure A.14: Effect on Health Outcomes, including May 2020 Data

(a) Number of cases (7-days difference)

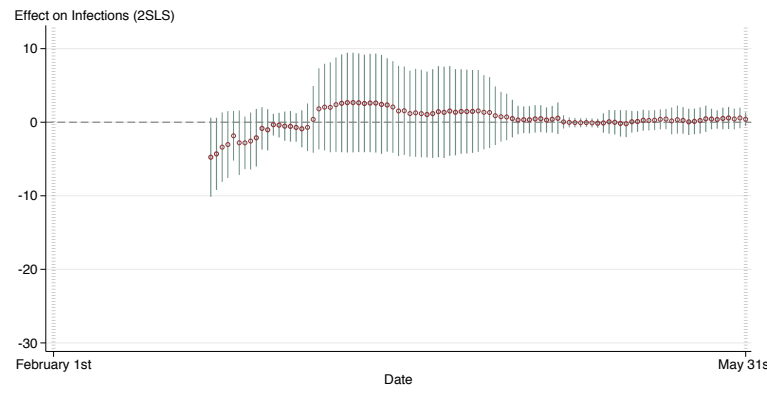

(c) Number of cases (per capita)

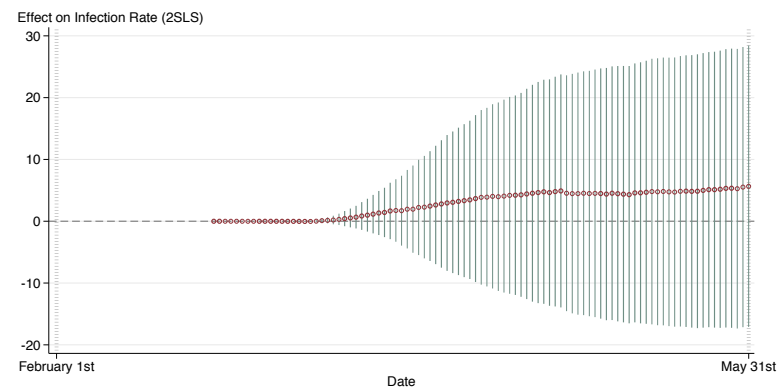

(b) Number of deaths (7-days difference)

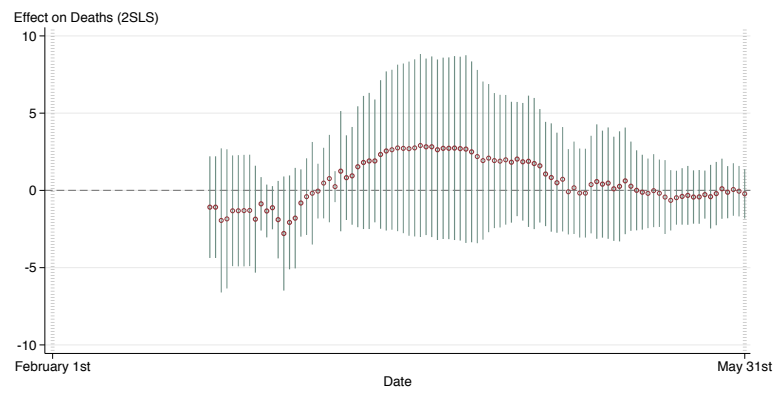

(d) Number of deaths (per capita)

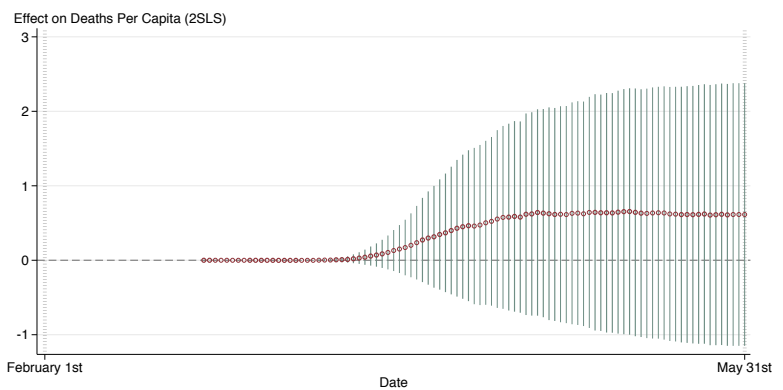

Notes: Each panel in this figure shows a series of coefficient plots and $95 \%$ confidence intervals for daily regressions of the effect of Fox News Channel viewership on a different outcome. The dependent variables are cases and deaths, we have two measures: a 7-days and the cumulative per capita measure. Specification is the same is in the main COVID-19 regressions in Figure 3. We include further data for May 2020. 
Figure A.15: Health Outcome Placebo Test: Effect on Seasonal Flu

(a) $2007-2009$

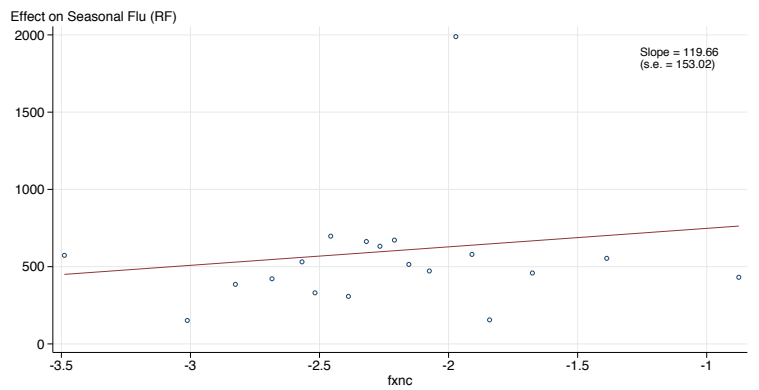

(c) $2013-2015$

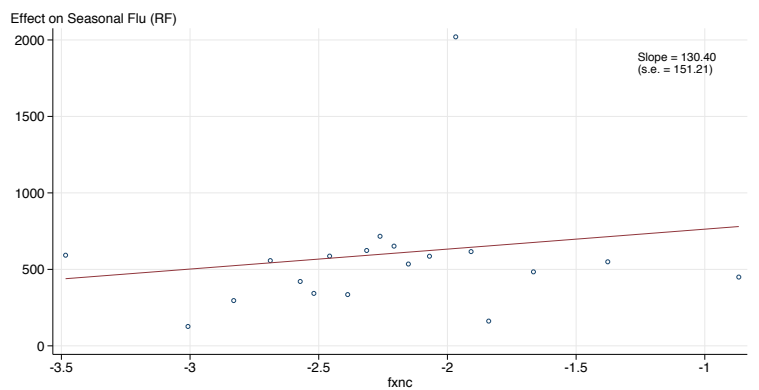

(b) $2010-2012$

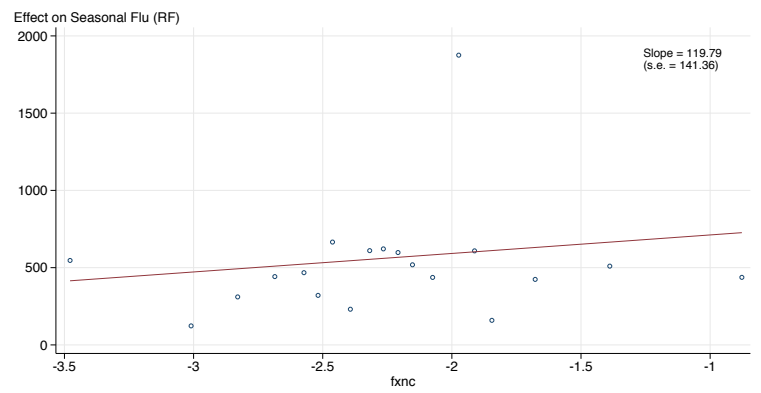

(d) $2016-2018$

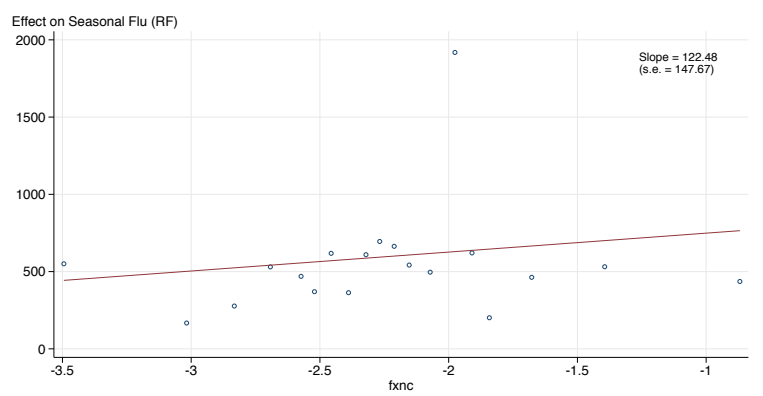

Notes: We look here at seasonal flu deaths from 2007 to 2018 pooled by three years. Specification is the same as the main regressions for COVID-19 but without baseline, with weighted observations, State FE's and State clustered standard errors, census controls, political elections controls and CNN and MSNBC ratings. 
Table A.6: 2SLS Estimates - Number of cases (7-days difference)

\begin{tabular}{|c|c|c|c|c|c|}
\hline Date & Coefficient & st. errors & Date & Coefficient & st. errors \\
\hline $29-F e b-20$ & -4.758 & $(2.668)$ & 31-Mar-20 & 2.346 & $(3.154)$ \\
\hline 01-Mar-20 & -4.306 & $(2.441)$ & 01-Apr-20 & 2.068 & (3.098) \\
\hline 02-Mar-20 & -3.388 & $(2.348)$ & 02-Apr-20 & 1.531 & $(3.049)$ \\
\hline 03-Mar-20 & -3.038 & $(2.258)$ & 03-Apr-20 & 1.561 & $(2.995)$ \\
\hline 04-Mar-20 & -1.848 & $(1.676)$ & 04-Apr-20 & 1.176 & $(2.901)$ \\
\hline 05-Mar-20 & -2.794 & $(2.183)$ & 05-Apr-20 & 1.276 & $(2.974)$ \\
\hline 06-Mar-20 & -2.806 & $(1.774)$ & 06-Apr-20 & 1.167 & $(2.957)$ \\
\hline 07-Mar-20 & -2.557 & $(1.926)$ & 07-Apr-20 & 1.047 & $(2.903)$ \\
\hline 08-Mar-20 & -2.114 & $(1.947)$ & 08-Apr-20 & 1.173 & $(2.996)$ \\
\hline 09-Mar-20 & -0.842 & $(1.430)$ & 09-Apr-20 & 1.433 & $(3.079)$ \\
\hline 10-Mar-20 & -1.032 & $(1.393)$ & 10-Apr-20 & 1.341 & $(3.091)$ \\
\hline 11-Mar-20 & -0.338 & $(0.733)$ & 11-Apr-20 & 1.526 & $(3.033)$ \\
\hline 12-Mar-20 & -0.397 & $(0.834)$ & 12-Apr-20 & 1.352 & $(2.914)$ \\
\hline 13-Mar-20 & -0.535 & $(0.988)$ & 13-Apr-20 & 1.460 & $(2.859)$ \\
\hline 14-Mar-20 & -0.563 & $(1.035)$ & 14-Apr-20 & 1.446 & $(2.836)$ \\
\hline 15-Mar-20 & -0.710 & $(0.965)$ & 15-Apr-20 & 1.471 & $(2.803)$ \\
\hline 16-Mar-20 & -0.895 & $(1.251)$ & 16-Apr-20 & 1.542 & $(2.768)$ \\
\hline 17-Mar-20 & -0.695 & (1.611) & 17-Apr-20 & 1.350 & $(2.513)$ \\
\hline 18-Mar-20 & 0.386 & $(2.260)$ & 18-Apr-20 & 1.318 & $(2.394)$ \\
\hline 19-Mar-20 & 1.820 & $(2.745)$ & 19-Apr-20 & 0.881 & $(1.982)$ \\
\hline 20-Mar-20 & 2.057 & $(2.934)$ & 20-Apr-20 & 0.745 & $(1.683)$ \\
\hline 21-Mar-20 & 2.022 & $(3.037)$ & 21-Apr-20 & 0.713 & $(1.573)$ \\
\hline 22-Mar-20 & 2.387 & $(3.187)$ & 22-Apr-20 & 0.495 & $(1.270)$ \\
\hline 23-Mar-20 & 2.571 & $(3.309)$ & 23-Apr-20 & 0.299 & $(0.961)$ \\
\hline 24-Mar-20 & 2.665 & $(3.376)$ & 24-Apr-20 & 0.340 & $(0.902)$ \\
\hline 25-Mar-20 & 2.671 & $(3.368)$ & 25-Apr-20 & 0.331 & $(0.918)$ \\
\hline 26-Mar-20 & 2.643 & $(3.338)$ & 26-Apr-20 & 0.449 & $(0.927)$ \\
\hline 27-Mar-20 & 2.547 & $(3.296)$ & 27-Apr-20 & 0.479 & $(0.914)$ \\
\hline 28-Mar-20 & 2.610 & $(3.324)$ & 28-Apr-20 & 0.298 & $(0.854)$ \\
\hline 29-Mar-20 & 2.607 & $(3.347)$ & 29-Apr-20 & 0.402 & $(0.904)$ \\
\hline 30-Mar-20 & 2.421 & $(3.342)$ & 30-Apr-20 & 0.540 & $(1.065)$ \\
\hline
\end{tabular}

Notes: Standard errors clustered by state. ${ }^{*} \mathrm{p}<0.05$ and ${ }^{* *} \mathrm{p}<0.01$. 
Table A.7: 2SLS Estimates - Number of deaths (7-days difference)

\begin{tabular}{lcc|lcc}
\hline Date & Coefficient & st. errors & Date & Coefficient & st. errors \\
\hline 29-Feb-20 & -1.084 & $(1.636)$ & 31-Mar-20 & 2.552 & $(2.561)$ \\
01-Mar-20 & -1.084 & $(1.636)$ & 01-Apr-20 & 2.632 & $(2.575)$ \\
02-Mar-20 & -1.943 & $(2.320)$ & 02-Apr-20 & 2.750 & $(2.680)$ \\
03-Mar-20 & -1.843 & $(2.240)$ & 03-Apr-20 & 2.722 & $(2.731)$ \\
04-Mar-20 & -1.319 & $(1.782)$ & 04-Apr-20 & 2.701 & $(2.803)$ \\
05-Mar-20 & -1.317 & $(1.790)$ & 05-Apr-20 & 2.752 & $(2.851)$ \\
06-Mar-20 & -1.307 & $(1.795)$ & 06-Apr-20 & 2.906 & $(2.946)$ \\
07-Mar-20 & -1.295 & $(1.793)$ & 07-Apr-20 & 2.821 & $(2.841)$ \\
08-Mar-20 & -1.863 & $(1.721)$ & 08-Apr-20 & 2.825 & $(2.907)$ \\
09-Mar-20 & -0.869 & $(0.860)$ & 09-Apr-20 & 2.632 & $(2.906)$ \\
10-Mar-20 & -1.332 & $(0.850)$ & 10-Apr-20 & 2.724 & $(2.920)$ \\
11-Mar-20 & -1.120 & $(0.695)$ & 11-Apr-20 & 2.727 & $(2.925)$ \\
12-Mar-20 & -1.893 & $(1.247)$ & 12-Apr-20 & 2.740 & $(2.961)$ \\
13-Mar-20 & -2.790 & $(1.836)$ & 13-Apr-20 & 2.704 & $(2.959)$ \\
14-Mar-20 & -2.070 & $(1.510)$ & 14-Apr-20 & 2.675 & $(3.021)$ \\
15-Mar-20 & -1.795 & $(1.618)$ & 15-Apr-20 & 2.496 & $(2.911)$ \\
16-Mar-20 & -0.816 & $(1.082)$ & 16-Apr-20 & 2.190 & $(2.789)$ \\
17-Mar-20 & -0.404 & $(1.234)$ & 17-Apr-20 & 1.929 & $(2.545)$ \\
18-Mar-20 & -0.185 & $(1.651)$ & 18-Apr-20 & 2.090 & $(2.385)$ \\
19-Mar-20 & -0.0450 & $(0.881)$ & 19-Apr-20 & 1.931 & $(2.174)$ \\
20-Mar-20 & 0.474 & $(1.137)$ & 20-Apr-20 & 1.893 & $(2.135)$ \\
21-Mar-20 & 0.766 & $(1.407)$ & 21-Apr-20 & 1.980 & $(2.088)$ \\
22-Mar-20 & 0.244 & $(0.499)$ & 22-Apr-20 & 1.824 & $(1.945)$ \\
23-Mar-20 & 1.246 & $(1.936)$ & 23-Apr-20 & 2.029 & $(1.839)$ \\
24-Mar-20 & 0.824 & $(1.363)$ & 24-Apr-20 & 1.853 & $(1.894)$ \\
25-Mar-20 & 0.942 & $(1.574)$ & 25-Apr-20 & 1.886 & $(2.113)$ \\
26-Mar-20 & 1.531 & $(1.946)$ & 26-Apr-20 & 1.740 & $(2.111)$ \\
27-Mar-20 & 1.808 & $(2.143)$ & 27-Apr-20 & 1.592 & $(1.827)$ \\
28-Mar-20 & 1.906 & $(2.192)$ & 28-Apr-20 & 1.061 & $(1.678)$ \\
29-Mar-20 & 1.909 & $(1.977)$ & 29-Apr-20 & 0.833 & $(1.744)$ \\
30-Mar-20 & 2.326 & $(2.391)$ & 30-Apr-20 & 0.497 & $(1.611)$ \\
\hline & & & &
\end{tabular}

Notes: Standard errors clustered by state. ${ }^{*} \mathrm{p}<0.05$ and ${ }^{* *} \mathrm{p}<0.01$. 


\section{A7. Additional Material on the Survey}

The survey was fielded between April 9th-14th using the online polls marketplace Lucid. Lucid utilizes an array of opt-in panels. Survey takers are compensated in cash, gift cards, or reward points. The large and diverse pool of respondents means that the average respondent takes 2.43 surveys per month (Coppock and McClellan, 2019).

We used quota sampling to ensure that the distributions of demographic characteristics (age, gender, ethnicity, race, education, income, and ZIP code) in our sample match the U.S. population margins, as measured by the census. Previous work has shown that the Lucid samples come closer than the MTurk platform to the demographic, political, and psychological characteristics of nationally representative samples (Coppock and McClellan, 2019). The final sample included 1480 respondents. Descriptive statistics are reported in Table A.8.

The survey was approved by the University of Tel Aviv Institutional Review Board.Informed consent was obtained from each participant at the beginning of the survey.

\section{Question Wording}

To assess the impact of FNC viewership on social-distancing behavior, respondents were asked: "Please indicate the last time you did any of the following activities:", followed by a matrix of the three behavioral outcomes:

- Eaten in a restaurant

- Visited a close friend at their home

- Spent time in the same room with more than five people

The response options were: (1) This week; (2) A week ago; (3) Two weeks ago; (4) Three weeks ago or more. The behavioral measure we use is computed as the mean response to the three items, providing an indication of the mean timing by respondents of taking steps toward social distancing.

Second, to gauge beliefs about the threat of the virus, and specifically the argument that COVID-19 can be effectively dealt with by existing treatments such as the antimalarial drug Hydroxychloroquine, we asked respondents: "Which of the following statements best describes the availability of a vaccine or an effective treatment for the coronavirus?". Response options were:

- A vaccine is already available 
- vaccine is not available but will be in less than a year

- A vaccine will be available in a year or more

- It is not possible to create a vaccine for the coronavirus

- There is no vaccine available but there are effective treatments (e.g., the drug Hydroxychloroquine).

We code a binary outcome Hydroxychloroquine as 1 if respondents chose the final option as the answer, consistent with the position advanced by leading programs on Fox News Channel. Overall, 27.1\% of respondents selected this option.

Finally, we code respondents' views pertaining to the policy debate on whether to sustain the lock-down measures given their impact of slowing economic activity. The question preamble read as follows: "People have different views on how the coronavirus outbreak should be managed. Some believe that the focus should be on avoiding economic depression and therefore that steps to contain the epidemic should be limited, even at the cost of more people who contract the virus. Others believe that minimizing the number of people who contract the virus should be the focus, even if that means taking expansive measures that bring about a severe economic decline. Where do you stand on this question?"

The respondents were then instructed as follows: "Please place yourself on the scale below.

- The right-hand side means the government should focus solely on minimizing the pandemic's harmful impact on the economy.

- The left-hand side means the government should focus on minimizing the pandemic's harmful impact on public health."

For ease of interpretation, we collapse the ratings to three levels: respondents placed priority on minimizing the negative impact on the economy, on public health, or assigned an equal priority.

In the top panel of Figure 5 the dependent variable is the average timing of the last instance the respondent carried out these three actions: participated in a gathering with more than five people; visited the house of a friend; dined in a restaurant. This is also the outcome measure in all four panels of Figure 6 . The panels differ in the sample 
we analyze: Panel (a) includes the full sample; Panel (b) includes only self-identified Republicans; Panel (c) includes Republicans who watch Fox at least two times a week; Panel (d) includes Republicans who are also self-identified conservatives. All estimates are obtained from regressions that control for gender, age, education, race, and state fixed effects. Standard errors are clustered by state. 
Table A.8: Summary Statistics: Survey Data

\begin{tabular}{|c|c|c|c|c|c|}
\hline Variable & Mean & Std. Dev. & Min & $\operatorname{Max}$ & $\mathrm{N}$ \\
\hline \multicolumn{6}{|l|}{ Televisions } \\
\hline Fox News & 0.564 & 0.496 & 0 & 1 & 1481 \\
\hline $\mathrm{CNN}$ & 0.542 & 0.498 & 0 & 1 & 1481 \\
\hline MSNBC & 0.452 & 0.498 & 0 & 1 & 1481 \\
\hline Hannity & 0.259 & 0.438 & 0 & 1 & 1481 \\
\hline Fox \& Friends & 0.344 & 0.475 & 0 & 1 & 1481 \\
\hline Tucker Carson Tonight & 0.255 & 0.436 & 0 & 1 & 1481 \\
\hline \multicolumn{6}{|l|}{ Attitudes $\&$ Beliefs } \\
\hline Changing Behavior & 3.529 & 0.700 & 1 & 4 & 1481 \\
\hline Hydroxcloroquine effective & 0.271 & 0.445 & 0 & 1 & 1481 \\
\hline Health-economic trade-off & 0.334 & 0.472 & 0 & 1 & 1481 \\
\hline \multicolumn{6}{|l|}{ Individual Characteristics } \\
\hline Age & 3.406 & 1.57 & 1 & 6 & 1481 \\
\hline Income & 4.455 & 2.336 & 1 & 9 & 1480 \\
\hline Female & 0.523 & 0.5 & 0 & 1 & 1481 \\
\hline Education & 3.331 & 1.532 & 1 & 6 & 1481 \\
\hline White & 0.614 & 0.487 & 0 & 1 & 1481 \\
\hline Hispanic & 0.175 & 0.38 & 0 & 1 & 1481 \\
\hline Black & 0.134 & 0.34 & 0 & 1 & 1481 \\
\hline Asian & 0.062 & 0.241 & 0 & 1 & 1481 \\
\hline Other & 0.016 & 0.124 & 0 & 1 & 1481 \\
\hline Republican & 0.328 & 0.47 & 0 & 1 & 1480 \\
\hline Independent & 0.281 & 0.45 & 0 & 1 & 1480 \\
\hline Democrat & 0.391 & 0.488 & 0 & 1 & 1480 \\
\hline
\end{tabular}


Table A.9: Cable News effect on attitudes and beliefs - Survey Estimates

\begin{tabular}{|c|c|c|c|c|}
\hline News Channel & $\begin{array}{c}\text { Coefficient } \\
\text { (1) }\end{array}$ & $\begin{array}{l}\text { st. errors } \\
\text { (2) }\end{array}$ & $\begin{array}{c}\text { Coefficient } \\
(3)\end{array}$ & $\begin{array}{l}\text { st. errors } \\
\text { (4) }\end{array}$ \\
\hline & \multicolumn{3}{|c|}{ Changing Behavior } & Leans Republican \\
\hline Fox News & $-0.121^{* *}$ & $(0.040)$ & -0.0858 & $(0.0472)$ \\
\hline $\mathrm{CNN}$ & 0.009 & $(0.041)$ & -0.00789 & $(0.0418)$ \\
\hline MSNBC & -0.055 & $(0.051)$ & -0.0635 & $(0.0507)$ \\
\hline & \multicolumn{4}{|c|}{$\begin{array}{l}\text { Hydroxcloroquine effective } \\
\text { Leans Republican }\end{array}$} \\
\hline Fox News & $0.124^{* *}$ & $(0.030)$ & $0.0833^{* *}$ & $(0.0284)$ \\
\hline $\mathrm{CNN}$ & -0.019 & $(0.030)$ & $-0.0687^{*}$ & $(0.0321)$ \\
\hline \multirow[t]{2}{*}{ MSNBC } & $-0.089^{* *}$ & $(0.030)$ & $-0.0790^{*}$ & $(0.0300)$ \\
\hline & \multicolumn{4}{|c|}{ Health-economic trade-off } \\
\hline Fox News & $0.220^{* *}$ & $(0.025)$ & $0.187^{* *}$ & $(0.0261)$ \\
\hline $\mathrm{CNN}$ & $-0.089 * *$ & $(0.033)$ & $-0.0687^{*}$ & $(0.0321)$ \\
\hline MSNBC & -0.037 & $(0.037)$ & 0.0468 & $(0.0336)$ \\
\hline
\end{tabular}

Notes: Standard errors clustered by state. ${ }^{*} \mathrm{p}<0.05$ and ${ }^{* *} \mathrm{p}<0.01$. 
Table A.10: Fox News shows effect on attitudes and beliefs - Survey Estimates

\begin{tabular}{|c|c|c|c|c|c|c|}
\hline News Channel & $\begin{array}{c}\text { Coefficient } \\
\text { (1) }\end{array}$ & $\begin{array}{l}\text { st. errors } \\
\text { (2) }\end{array}$ & $\begin{array}{c}\text { Coefficient } \\
\text { (3) }\end{array}$ & $\begin{array}{l}\text { st. errors } \\
\text { (4) }\end{array}$ & $\begin{array}{c}\text { Coefficient } \\
\text { (5) }\end{array}$ & $\begin{array}{l}\text { st. errors } \\
(6)\end{array}$ \\
\hline & \multicolumn{6}{|c|}{ Full Sample } \\
\hline & \multicolumn{2}{|c|}{ Changing Behavior } & \multicolumn{2}{|c|}{ Hydroxcloroquine effective } & \multicolumn{2}{|c|}{ Health-economic trade-off } \\
\hline Hannity & $-0.338 * *$ & $(0.0929)$ & 0.0851 & $(0.0367)$ & 0.0819 & $(0.042)$ \\
\hline Tucker Carson Tonight & -0.00729 & $(0.0418)$ & $0.0799 *$ & $(0.0279)$ & -0.0082 & $(0.0317)$ \\
\hline \multirow[t]{3}{*}{ Fox \& Friends } & -0.000937 & $(0.0769)$ & 0.137 & $(0.0524)$ & 0.0913 & $(0.044)$ \\
\hline & \multicolumn{6}{|c|}{ Republicans only } \\
\hline & \multicolumn{2}{|c|}{ Changing Behavior } & \multicolumn{2}{|c|}{ Hydroxcloroquine effective } & \multicolumn{2}{|c|}{ Health-economic trade-off } \\
\hline Hannity & -0.376 & $(0.142)$ & 0.103 & $(0.0987)$ & 0.0749 & $(0.0632)$ \\
\hline Tucker Carson Tonight & 0.00312 & $(0.0727)$ & 0.0481 & $(0.0433)$ & -0.0141 & $(0.0542)$ \\
\hline \multirow[t]{3}{*}{ Fox \& Friends } & 0.245 & $(0.136)$ & 0.0654 & $(0.0892)$ & 0.0881 & $(0.0824)$ \\
\hline & \multicolumn{6}{|c|}{ Republicans who are Fox News viewers } \\
\hline & \multicolumn{2}{|c|}{ Changing Behavior } & \multicolumn{2}{|c|}{ Hydroxcloroquine effective } & \multicolumn{2}{|c|}{ Health-economic trade-off } \\
\hline Hannity & -0.394 & $(0.184)$ & 0.0917 & $(0.0965)$ & 0.0173 & $(0.0789)$ \\
\hline Tucker Carson Tonight & -0.000 & $(0.0888)$ & 0.0374 & $(0.0677)$ & 0.0295 & $(0.0559)$ \\
\hline \multirow[t]{3}{*}{ Fox \& Friends } & 0.264 & $(0.162)$ & 0.0701 & $(0.0904)$ & 0.0974 & $(0.0937)$ \\
\hline & \multicolumn{6}{|c|}{ Republicans who are Conservatives } \\
\hline & \multicolumn{2}{|c|}{ Changing Behavior } & \multicolumn{2}{|c|}{ Hydroxcloroquine effective } & \multicolumn{2}{|c|}{ Health-economic trade-off } \\
\hline Hannity & -0.297 & $(0.163)$ & 0.128 & $(0.113)$ & 0.0567 & $(0.0877)$ \\
\hline Tucker Carson Tonight & -0.109 & $(0.0905)$ & 0.0151 & $(0.0679)$ & -0.0161 & $(0.0707)$ \\
\hline Fox \& Friends & 0.298 & $(0.176)$ & 0.0756 & $(0.102)$ & 0.0758 & $(0.1)$ \\
\hline
\end{tabular}

